\title{
Vitamin A supplements for preventing mortality, illness, and blindness in children aged under 5: systematic review and meta-analysis
}

\author{
OPEN ACCESS
}

\author{
Evan Mayo-Wilson departmental lecturer ${ }^{1}$, Aamer Imdad senior research officer ${ }^{2}$, Kurt Herzer \\ Marshall scholar ${ }^{1}$, Mohammad Yawar Yakoob senior research officer ${ }^{2}$, Zulfiqar A Bhutta Noordin \\ Noormahomed Sheriff endowed professor and founding chair ${ }^{2}$
}

${ }^{1}$ Centre for Evidence-Based Intervention, Department of Social Policy and Intervention, University of Oxford, Barnett House, Oxford OX1 2ER, UK; ${ }^{2}$ Division of Women and Child Health, Aga Khan University Hospital, Stadium Road, PO Box 3500, 74800 Karachi, Pakistan

\begin{abstract}
Objective To determine if vitamin A supplementation is associated with reductions in mortality and morbidity in children aged 6 months to 5 years.

Design Systematic review and meta-analysis. Two reviewers independently assessed studies for inclusion. Data were double extracted; discrepancies were resolved by discussion. Meta-analyses were performed for mortality, illness, vision, and side effects.
\end{abstract}

Data sources Cochrane Central Register of Controlled Trials (CENTRAL) in the Cochrane Library, Medline, Embase, Global Health, Latin American and Caribbean Health Sciences, metaRegister of Controlled Trials, and African Index Medicus. Databases were searched to April 2010 without restriction by language or publication status.

Eligibility criteria for selecting studies Randomised trials of synthetic oral vitamin A supplements in children aged 6 months to 5 years. Studies of children with current illness (such as diarrhoea, measles, and HIV), studies of children in hospital, and studies of food fortification or $\beta$ carotene were excluded.

Results 43 trials with about 215633 children were included. Seventeen trials including 194483 participants reported a 24\% reduction in all cause mortality (rate ratio $=0.76,95 \%$ confidence interval 0.69 to 0.83 ). Seven trials reported a $28 \%$ reduction in mortality associated with diarrhoea $(0.72,0.57$ to 0.91$)$. Vitamin A supplementation was associated with a reduced incidence of diarrhoea $(0.85,0.82$ to 0.87$)$ and measles $(0.50$, 0.37 to 0.67 ) and a reduced prevalence of vision problems, including night blindness $(0.32,0.21$ to 0.50$)$ and xerophthalmia $(0.31,0.22$ to $0.45)$. Three trials reported an increased risk of vomiting within the first 48 hours of supplementation $(2.75,1.81$ to 4.19$)$.
Conclusions Vitamin A supplementation is associated with large reductions in mortality, morbidity, and vision problems in a range of settings, and these results cannot be explained by bias. Further placebo controlled trials of vitamin A supplementation in children between 6 and 59 months of age are not required. However, there is a need for further studies comparing different doses and delivery mechanisms (for example, fortification). Until other sources are available, vitamin A supplements should be given to all children at risk of deficiency, particularly in low and middle income countries.

\section{Introduction}

Vitamin A refers to a subclass of retinoic acids ${ }^{1}$ long understood to help regulate immune function and to reduce morbidity of infectious diseases. ${ }^{2}$ Vitamin $\mathrm{A}$ is required for normal functioning of the visual system, maintenance of cell function for growth, epithelial integrity, production of red blood cells, immunity, and reproduction. ${ }^{3}$ Different forms of vitamin A include $\beta$ carotene, which is found in plants, and preformed vitamin $\mathrm{A}$, which is found in animal sources. Vitamin A is an essential nutrient that cannot be synthesised so it must be obtained through diet. ${ }^{1}$

Vitamin A deficiency increases vulnerability to a range of illnesses including diarrhoea, measles, and respiratory infections. ${ }^{34}$ These are leading causes of mortality among children in low and middle income countries, ${ }^{5}$ where risk of infection and risk of mortality can be compounded by coexisting undernutrition. ${ }^{6}$ The bioavailability of provitamin A carotenoids in fruit and vegetables is lower than once believed, ${ }^{78}$ and it is difficult for children to fulfil their daily requirements through plant foods alone. Consequently, vitamin A deficiency is 
common among children whose families cannot afford eggs and dairy products.

Preformed vitamin A (retinol, retinal, retinoic acid, and retinyl esters) is the most active in humans; it is usually used in supplements in the form of retinyl esters. ${ }^{13}$ High intake of synthetic vitamin A over a prolonged period can lead to toxicity, ${ }^{9}$ but toxicity from food sources is rare. Periodic supplementation should not cause serious adverse effects. ${ }^{10}$

Previous meta-analyses suggested that vitamin A supplementation for children in developing countries is associated with up to $30 \%$ reductions in mortality, ${ }^{11-13}$ especially deaths from diarrhoea and measles. The World Health Organization has long recommended vitamin A supplementation for children aged under 5 and for pregnant and breastfeeding mothers. ${ }^{14}$ The Countdown to 2015 identified 68 "priority countries" in which over $90 \%$ of the world's maternal and childhood deaths occur ${ }^{15}$; the programme aims to hold governments accountable for their commitments to Millennium Development Goals. Vitamin A is now being provided in many low and middle income countries with coverage rates of $86 \% .^{15}$ Nonetheless, some critics have questioned the value and effectiveness of vitamin A supplementation programmes, and several studies have been conducted since initial recommendations were made. ${ }^{16} 17$

We undertook a review to synthesise all available evidence for vitamin A supplementation in children aged 6 months to 5 years, adding to previous reviews by investigating effects on mortality and the illnesses that lead to death. By investigating all effects in the same review, we provided current estimates of treatment effects and identified potential pathways through which vitamin A supplementation might reduce mortality. A complete protocol was peer reviewed and published by the Cochrane Collaboration, and the review is available in the Cochrane Library. ${ }^{18}$

\section{Methods}

We evaluated the effect of prophylactic synthetic oral vitamin A supplementation compared with no treatment or placebo. We planned to conduct five subgroup analyses:

- Dose: WHO recommended dose (up to $100000 \mathrm{IU}$ for children aged 6-11 months and 200000 IU for children aged 1-5 years) $v$ lower and higher doses

- Frequency: high (doses within 6 months) $v$ low (1 dose or $\geq 6$ month interval)

- Location: by continent

- Age: 6-12 months $v$ 1-5 years

- Sex: boys $v$ girls.

\section{Eligibility criteria}

Types of trials—Randomised controlled trials including cluster trials and factorial trials were included irrespective of publication status or language.

Types of participants - At the time of recruitment, children had to be aged 6 months to 5 years and apparently healthy. Children in hospital at the time of recruitment were excluded.

Types of interventions - Included studies examined synthetic oral vitamin A supplementation compared with no treatment or placebo, irrespective of dose or frequency. Studies of food fortification and $\beta$ carotene supplementation were excluded as their effects can differ.

\section{Types of outcome measures}

Primary-We examined all cause mortality at the longest follow-up. We also analysed outcomes within the first year and more than one year after supplementation.

Secondary-We analysed cause specific mortality from diarrhoea, lower respiratory tract infection, measles, and meningitis. We compared the incidence and prevalence of diarrhoea, lower respiratory tract infection, measles, malaria, meningitis, Bitot's spots, night blindness, and xerophthalmia. Adverse events were noted and analysed when possible (vomiting and bulging fontanelle). Finally, we examined vitamin A status (serum retinol) as a continuous and dichotomous outcome.

\section{Search strategy}

We searched the Cochrane Central Register of Controlled Trials (CENTRAL 2010, issue 2), Medline (see box), Embase, Global Health, Latin American Database (LILACS), metaRegister of Controlled Trials, and African Index Medicus (see appendix 1 on bmj.com). All searches were conducted on 27 April 2010. To identify ongoing and unpublished trials, we used the WHO international clinical trials registry, which searches multiple trial registries. Reference lists of reviews, included studies, and excluded studies were searched for additional citations. We contacted organisations and researchers by email and by phone. Two authors (from AI, KH, and MYY) independently screened abstracts and resolved differences with a third author (EMW).

\section{Assessment of bias}

Studies were assessed with the Cochrane Collaboration's risk of bias tool. ${ }^{19}$ Two authors rated each study for risk of bias from sequence generation (was the method truly random?), allocation concealment (before enrolment, were participants' group assignments disguised?), blinding of participants, assessors, and providers (was assignment adequately disguised after randomisation?), selective outcome reporting (were all outcome measures reported?), and incomplete data (do the results account for all participants randomised?). Risk of bias for each domain was rated as high (seriously weakens confidence in the results), low (unlikely to seriously alter the results), or unclear. Discrepancies were resolved through discussion. The primary analysis was repeated without studies at high risk of bias for sequence generation.

\section{Data management}

Two independent people, at least one of whom was an author, completed data extraction and assessments of risk of bias online with Distiller software. ${ }^{20}$ We collected data on the time points and measures (both collected and reported) and recruitment, inclusion/exclusion criteria, co-interventions, dose, frequency, duration, age, sex, setting, and location.

\section{Statistical analysis}

For continuous outcomes, we calculated the standardised mean difference, Hedges' g. ${ }^{21}$ For dichotomous outcomes, we calculated an overall risk ratio. For incidence data, risk ratio (events per child) and rate ratio (events per child year) were combined because these ratios use the same scale and can be interpreted in the same way for these studies (the duration of studies was short and there was no interaction between the intervention and time at risk). All outcomes are reported with $95 \%$ confidence intervals, and overall effects are weighted by the inverse of variance with a fixed effect model. In the case of 


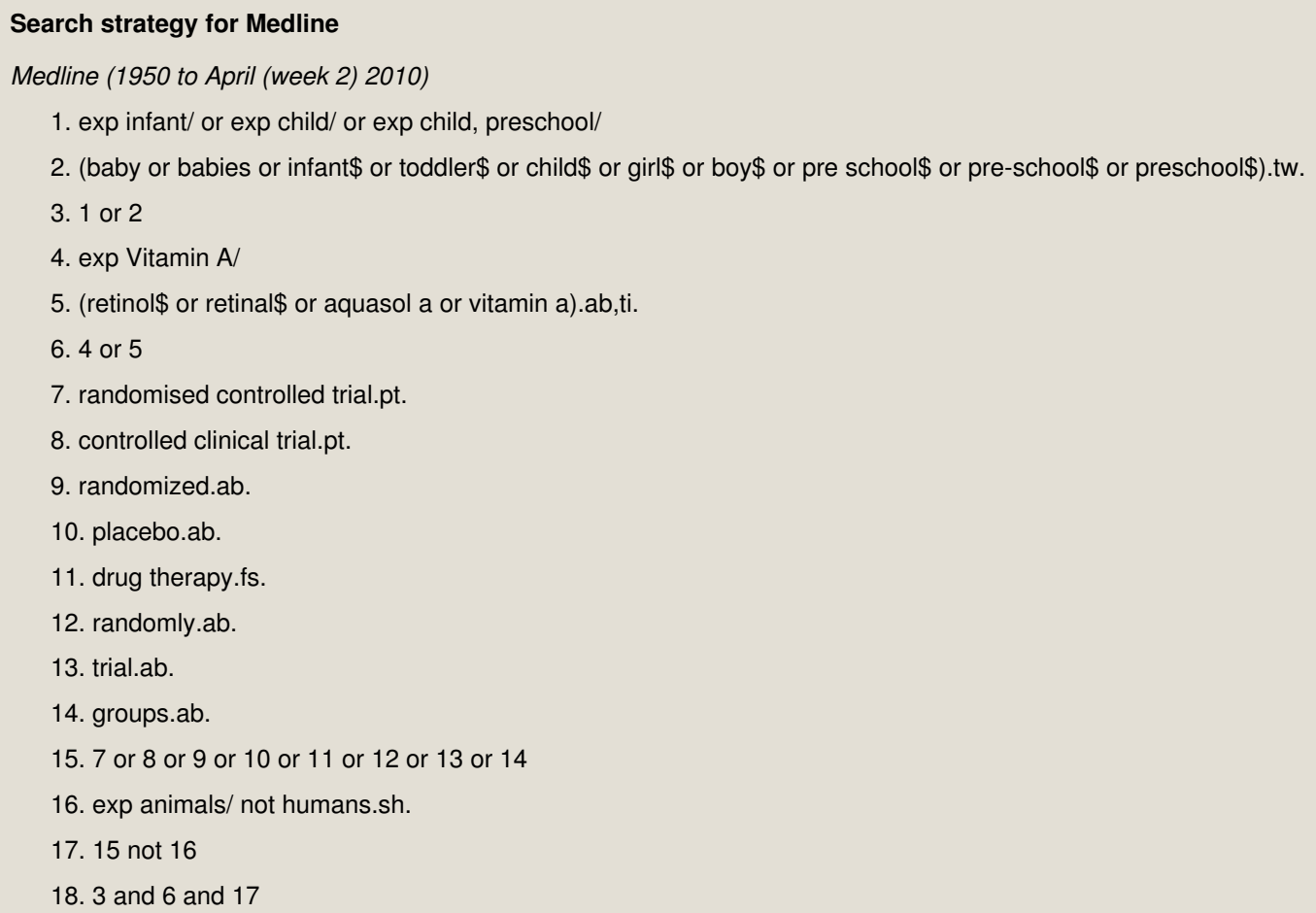

cluster randomised controlled trials, we used adjusted estimates reported by the authors. Where results did not control for clustering, we contacted authors to request the intracluster correlation coefficient. If authors were unable to provide this, we used design effects calculated previously ${ }^{11}$ to calculate it using Cochrane methods. ${ }^{19}$ For estimated values, we conducted sensitivity analyses using larger and smaller design effects to determine if the results were robust.

Missing data were noted for each outcome. When the numbers of dropouts were not reported, we contacted the authors. When analyses were reported for completers as well as controlled for dropouts (for example, imputed with regression methods), we used the latter.

Statistical heterogeneity was assessed by visual inspection of forest plots, by performing $\chi^{2}$ tests (assessing the $\mathrm{P}$ value), and by calculating the $\mathrm{I}^{2}$ statistic, ${ }^{22}{ }^{23}$ which describes the percentage of observed heterogeneity that would not be expected by chance. If the $\mathrm{P}$ value was less than 0.10 and $\mathrm{I}^{2}$ exceeded $50 \%$, we considered heterogeneity to be substantial. In subgroup analyses, we tested differences between groups with $\chi^{2}$. To assess the possibility of small study bias, we compared random effects estimates with fixed effects estimates, drew funnel plots for outcomes with 10 or more studies, and conducted a trim and fill analysis, ${ }^{24}$ which yields an effect adjusted for funnel plot asymmetry. Meta-analysis was conducted with RevMan ${ }^{25}$ and Biostat CMA (comprehensive meta-analysis) ${ }^{26}$ and a summary of results was prepared with the GRADE system. ${ }^{27}$

\section{Results}

\section{Trial flow}

We included 43 trials $^{28-69}$ reported in 90 papers; 39 (90\%) reported data that could be included in a meta-analysis (fig $1 \Downarrow$ ). The others reported outcomes that were not relevant to the review $^{35}$ and data that were not available by group ${ }^{43}$ or were incomplete. ${ }^{62}{ }^{66}$ Post hoc, we included two studies in which participants were assigned using quasi-random methods (alternating assignment) as described below. ${ }^{41} 65$
Eight trials nearly met the inclusion criteria but were excluded because they were not randomised controlled trials, ${ }^{70-73}$ were designed to treat diarrhoea ${ }^{74}$ or Bitot's spots, ${ }^{75}$ focused on children with HIV ${ }^{76}$ or did not include an eligible comparison. ${ }^{77}$

Two trials could not be assessed at this time. One including 36 children could not be located and is unlikely to affect the results. ${ }^{78}$ One completed trial, the deworming and vitamin A (DEVTA) trial, seems likely to meet the eligibility criteria and could be included in further updates of this review. ${ }^{79}$ To assess how the results of that trial could affect the conclusions of our review, we conducted a sensitivity analysis for the primary outcome.

\section{Study characteristics}

Trials included 215633 participants with a median sample size of 480 , ranging from $35^{66}$ to over $29000 .^{63}$ The 39 trials that were analysed included 215043 participants $(99.8 \%$ of children included in the review).

Of the 43 included trials, 37 compared vitamin A supplementation with placebo. Four used factorial designs, combining vitamin A supplementation with other treatments such as zinc ${ }^{465162}$ or deworming. ${ }^{55}$ In one trial, ${ }^{51}$ raw data were not available and we could not identify outcome data for an eligible comparison. Different doses were combined for the main analysis in one trial. ${ }^{40}$

The median of the mean ages was 30.5 months. Most trials assigned equal numbers of boys and girls; three studies favoured boys by more than $10 \%{ }^{45} 5457$ When trials reported outcomes at multiple time points, we analysed the longest follow-up; most studies lasted about one year. Table $1 \Downarrow$ describes characteristics for individual studies, and table $2 \Downarrow$ shows counts for subgroup characteristics.

\section{Risk of bias}

Figure 2 shows the risk of bias ratings ${ }^{19}$ for each trial. $\Downarrow$ Three trials were at high risk of bias for sequence generation (not truly random), and these included 41139 participants. ${ }^{29} 4165$ In two 
quasi-random studies (included post hoc), the authors and the Cochrane editors agreed that the methods of assignment had the desirable characteristics of randomisation and were at no greater risk of bias than other included studies. Only one study was at high risk of bias because of inadequate allocation concealment, but concealment of the allocation sequence was not sufficiently described in 27 trials.

Lack of blinding of assessors created a high risk of bias in only two studies, but it was unclear if assessors were blind in 14

trials. Two studies were at high risk of bias for failing to blind project staff, and 13 trials were unclear on this issue. At the trial level, nine were at high risk of bias for missing data and 12 were unclear, though missing data for the primary outcome was not a concern.

Only four studies seemed to be completely free from selective outcome reporting. It was unclear if 24 trials reported all outcomes, but the primary outcome (mortality) was known for almost all participants in the review. To test for bias, the primary analysis was repeated without studies at high risk of bias for sequence generation.

\section{Quantitative data synthesis}

\section{All cause mortality}

Mortality (fig $3 \Downarrow$ ) was reported in 17 trials including 194483 children (90\% of the children in the review); one reported no events and was not analysed. ${ }^{45}$ Thus, 16 trials were included in the primary meta-analysis. Two studies ${ }^{4165}$ randomised households, and we treated them as if they had randomised individuals. Previously reported design effects ${ }^{11}$ were used to calculate intracluster correlation coefficients for six cluster randomised studies. ${ }^{375256636869}$ The coefficients were consistent, and we imputed an intracluster correlation coefficient of 0.002 for all studies in which clustering was not considered in the original analysis. A sensitivity analysis was conducted for all cause mortality with coefficients of 0 and 0.01 for those studies in which the mean design effect was estimated.

Vitamin A was associated with a $24 \%$ reduction in all cause mortality $(0.76,95 \%$ confidence interval 0.69 to 0.83 ; fig 3$)$, though there was moderate heterogeneity $\left(\chi^{2}=29.10, \mathrm{df}=15\right.$, $\mathrm{P}=0.02 ; \mathrm{I}^{2}=48 \%$ ). Only five trials 3638485668 (7\% of trials) measured mortality after 13 months, and the effect was similar $(0.75,0.64$ to 0.88$)$ with substantial and significant heterogeneity $\left(\chi^{2}=9.29, \mathrm{df}=4, \mathrm{P}=0.05 ; \mathrm{I}^{2}=57 \%\right)$.

We then added a study awaiting assessment to the analysis. ${ }^{79}$ In an analysis of 17 trials, this study (the deworming and vitamin A trial) accounted for $65.2 \%$ of the combined effect (fig $4 \Downarrow$ ), which remained significant $(0.88,0.84$ to 0.94$)$ with substantial and significant heterogeneity $\left(\chi^{2}=44.31, \mathrm{df}=16, \mathrm{P}<0.001\right.$; $\left.\mathrm{I}^{2}=64 \%\right)$. Though the benefit of vitamin A decreased by half ( $24 \%$ to $12 \%$ ), the result remained clinically important. As we were unable to assess the trial, we cannot explain this substantially different result; its impacts on the conclusions of this review are considered below.

Of those in the main analysis, 10 trials were conducted in Asia, five in Africa, and one in Latin America. There was no clear difference $(\mathrm{P}=0.12)$ between the Asia subgroup $(0.69,0.61$ to 0.79 ) and the Africa subgroup ( $0.85,0.73$ to 0.98$)$, though the Latin American trial reported no effect (1.00, 0.14 to 7.08$)$. We planned to compare trials in urban and rural areas, but only two urban trials reported the primary outcome; an analysis comparing 1982 and 192501 participants would be difficult to interpret.

Four trials reported separate effects for children aged 6-12 months $(0.59,0.43$ to 0.82$)$ and children aged $1-5$ years $(0.68$,
0.57 to 0.82 ); the subgroups did not differ significantly ( $\mathrm{P}=0.46$ ). Five trials reported separate effects for boys ( $0.80,0.66$ to 0.97$)$ and girls $(0.79,0.65$ to 0.95$)$, which were not significantly different $(\mathrm{P}=0.89)$. Notably, effects for sex and age subgroups are all larger than the overall result, and these results should be interpreted with caution.

Only one trial providing small frequent doses reported mortality data, and the effects were larger $(0.46,0.30$ to 0.71$)$ than the effects for the WHO recommended dose delivered every four to six months $(0.81,0.72$ to 0.90$)$ or the recommended dose delivered once $(0.66,0.52$ to 0.83$)$. Differences between subgroups were significant $(\mathrm{P}=0.02)$, but only the greater effect for small frequent doses seems clinically plausible (fig $5 \Downarrow$ ).

Of the trials at high risk of bias from sequence generation, only one contributed to primary analysis, and it reported no effect (1.06, 0.82 to 1.37$)$, indicating that these trials were not likely to inflate the combined effect.

The primary analysis was repeated with a random effects model, and the overall estimate was slightly larger; thus, heterogeneity is partially explained by small studies reporting larger effects ( $0.71,0.61$ to 0.84$)$, which could be related to bias or to clinical differences (such as better implementation in small trials). We drew a funnel plot and conducted a trim and fill analysis (fig $6 \Downarrow$ ). There was some evidence of asymmetry (five studies trimmed), but the overall effect was strongly influenced by five studies that accounted for over $80 \%$ of the weighted mean, and there was no effect of replacing missing studies (adjusted value rate ratio $=0.80,0.73$ to 0.87 ).

We also conducted a sensitivity analysis to determine if the intracluster correlation coefficients used to adjust for clustering influenced the overall effect. The size of the effect was slightly smaller when these trials were treated as if they had randomised individuals ( $0.81,0.75$ to 0.89$)$ and was unchanged when we increased the coefficient to 0.01 (0.75, 0.68 to 0.83$)$. Adjusting three studies for which the intracluster correlation coefficients was unknown did not affect our conclusions; further inflating their standard errors would increase the size of the overall effect.

\section{Cause specific mortality}

Vitamin A supplementation was associated with a $27 \%$ reduction in deaths from diarrhoea. Differences in deaths from measles and meningitis were not significant (table $3 \Downarrow$ ).

\section{Morbidities}

Morbidity was measured in different ways, and we combined all available data whenever possible. For example, for diarrhoea we included all types of diarrhoea (mild, moderate, and severe). Pneumonia and lower respiratory tract infection outcomes were combined post hoc because pneumonia is a type of lower respiratory tract infection and many studies did not have complete diagnostic information.

Overall, there was a $15 \%$ decrease in diarrhoea incidence (fig $7 \Downarrow$ ) and a $50 \%$ decrease in incidence of measles (fig $8 \Downarrow$ ); heterogeneity in the former analysis was substantial, but heterogeneity in the second was not important. Only one trial reported incidence of malaria, which showed a reduction, and effects on lower respiratory infections were not significant (table $3 \Downarrow$ ). Few studies reported prevalence data; results for diarrhoea and malaria were not significant, and there were no data for measles. 


\section{Vision}

Evidence for vision outcomes was based on a small number of small studies. The available studies suggest a large reduction in the incidence and prevalence of night blindness and a large reduction in the prevalence of xerophthalmia, but effects on Bitot's spots and the incidence of xerophthalmia were not significant (table $4 \Downarrow$ ).

\section{Vitamin A deficiency}

Serum concentrations were measured in a small number of small studies. These suggest that vitamin A supplementation reduces the proportion of children who are deficient and increases vitamin A serum concentrations (table $4 \Downarrow$ ), but heterogeneity was substantial. These results could be influenced by bias, and serum concentrations might be a poor indicator of vitamin A status.

\section{Adverse events}

Three trials reported that high doses of vitamin A triple the risk of vomiting within 48 hours. Results for fontanelle side effects were not significant in one study (table 4), and two studies that measured the outcome could not be analysed.

\section{Discussion}

Comparable with previous reviews, this review shows that vitamin A supplementation is associated with large and important reductions in mortality for children in low and middle income countries. This adds substantively to previous reviews $\mathrm{s}^{11-13}$ in providing a plausible pathway and indicating that vitamin $\mathrm{A}$ supplementation reduces the incidence of and mortality from diarrhoea and measles. Vitamin A also reduces precursors to blindness. While there was a slight increase in the risk of vomiting within 48 hours, there was no evidence of serious adverse events as a result of periodic supplementation. Most trials did not measure vitamin A serum concentrations at baseline as children are unlikely to experience serious harm under these conditions; continuous supplementation, however, might lead to toxicity and cause more severe side effects. It is unclear if smaller more frequent doses would lead to the same minor side effects observed in this review. ${ }^{9}$

Vitamin A deficiency is common during childhood in many low and middle income countries, even among populations whose diets rely heavily on vegetables and fruits. ${ }^{80}$ The reasons are multiple and include widespread maternal undernutrition, poor dietary quality, and losses during diarrhoea. ${ }^{81}{ }^{82} \mathrm{WHO}$ estimates that 122 countries have a moderate to severe public health problem. ${ }^{83}$

\section{Strengths and limitations}

For the primary outcome, the evidence in this review is strong. Sixteen studies were analysed, which included a large number of children. Subgroup and sensitivity analyses show that the result is robust and the effects of bias were not important.

For the primary outcome, the quality of the evidence was "high" on the GRADE scale ${ }^{27}$ - that is, further trials are unlikely to change the conclusion that vitamin A supplementation has a large and significant effect (table 3). It seems unlikely that the primary outcome is significantly overestimated because of bias from any source. Almost all studies were randomised with appropriate methods for sequence generation, and allocation was well concealed. It was easy to blind participants and providers, and most trials reported that people were unaware of the treatments being provided. Furthermore, lack of blinding might underestimate rather than overestimate effects-for example, a teacher might give extra food to a child receiving a placebo. Failure to blind assessors is unlikely to influence mortality data. Risks of selective outcome reporting and publication bias are low; the primary analysis included nearly all participants who had been randomised, and all studies large enough to make a difference in this analysis are probably known.

Two trials at high risk of bias for sequence generation were included post hoc, but steps to maintain allocation concealment and blinding minimised the possibility that participants were treated differently between groups. In the first, participants were assigned alternately by household. ${ }^{41}$ The second used a random starting point and alternating distribution of red or green pills; the manufacturer held the code until the study was completed. ${ }^{65}$ The decision to include these studies was made before data were extracted, and the one study that contributed to the primary outcome $^{41}$ reported no effect $(1.06,0.82$ to 1.37$)$. The decision to include these studies did not result in an overestimation of the primary outcome.

This review makes an important contribution by identifying several pathways though which vitamin A could reduce mortality. Much of the reduction in all cause mortality is probably explained by reductions in death from diarrhoea and measles, which are leading contributors to child mortality in low and middle income countries. ${ }^{5}$ This hypothesis is strengthened by a review indicating that vitamin A supplementation prevents acute diarrhoea from becoming chronic. ${ }^{84}$ Though the overall effect for mortality from measles was not significant, the trend was consistent with the overall results, and the therapeutic effects of vitamin A supplementation for measles are well established. ${ }^{78}$

For the secondary outcomes, the quality of the evidence was variable on the GRADE scale (tables 3 and 4), though evidence for measles incidence was high quality. We downgraded ratings for diarrhoea and measles mortality to "moderate" because of uncertainty about the size of the effects; these results are consistent with other findings and consistent with biological mechanisms through which vitamin A supplementation could cause an overall reduction in mortality.

In general, large studies examined effects on mortality while small studies measured illness, vision, and vitamin A serum concentrations. A few studies measured growth, though we did not include this as an outcome. Different outcomes are appropriate for studies with different purposes, but many secondary analyses include only a small proportion of the participants in the review. Recent evidence suggests that the prevalence of selective reporting of outcomes is high and that this might substantially bias systematic reviews. ${ }^{85} 86$ If outcomes were reported selectively, addition of unreported data might influence the observed effects in some secondary analyses; we have more confidence in the internal validity of the primary outcome than the secondary outcomes.

Secondary outcomes also have less external validity than the primary analysis, and differences in the size of included studies could mask differences in the size of the analyses. For example, the primary analysis includes 16 trials while analyses for incidence of diarrhoea and serum concentration include 12 and 13 trials. Only five trials appear in both the primary analysis and the diarrhoea analysis, and only three appear in both the primary and serum analyses. While the primary outcome includes 194483 participants (90\% of those randomised), the analysis of incidence of diarrhoea includes only 37710 (17\%) and the serum analysis includes 6623 (that is, less than $3 \%$ of participants in the review). To draw attention to these differences 
in external validity and risk of bias, tables 3 and 4 include the number of participants in each analysis as a percentage of those randomised. ${ }^{87}$

\section{Comparison with earlier reviews}

Landmark reviews of vitamin A for children appeared in 1993. ${ }^{113}$ Since then, nine studies contributing $30 \%$ of the children in this review have improved the quality of the evidence for vitamin A supplementation in children aged under 5 years.

For the primary outcome, we conducted a cumulative meta-analysis (fig $9 \Downarrow$ ) to show how the effect has shifted with the addition of studies over time. That is, each point on the plot shows the combined effect of the new study and all studies reported before it, and the weight is the combined weight of all studies up to that time. Eight trials were included in a 1993 review, ${ }^{11}$ which reported a $23 \%$ reduction in all cause mortality $(0.77,0.70$ to 0.86$)$. Eight trials were added to this analysis (one additional trial reported no events), and the overall estimate has changed by $1 \%$. The overall effect is not meaningfully different from the result of the first trial published in 1986. Therefore, this review confirms that previous estimates remain valid, finding little evidence of secular trends.

Supplementation in other populations is more controversial. A recent review of vitamin A supplementation for children aged under 6 months found no overall effect, but differences between regional subgroups might have been important. ${ }^{88}$

\section{Comparison with the deworming and vitamin A (DEVTA) trial}

The most important qualification of these findings is that a large study, awaiting assessment, found no benefit of vitamin A supplementation. Some reviews have found only fair agreement between the results of meta-analyses and the results of large trials ${ }^{89}$; in extreme cases, large trials might indicate that the combined results of smaller trials are incorrect in magnitude or direction. ${ }^{90}$ When the results of large trials differ from the results of small trials, commonly used methods for meta-analysis could be inappropriate. ${ }^{91}$ All things being equal (such as risk of bias and implementation), researchers and clinicians have been advised to trust large simple trials rather than meta-analyses of small trials. ${ }^{92} 93$

The deworming and vitamin (DEVTA) trial is the largest randomised controlled trial ever conducted, including about a million children in 72 clusters, more than four times the number of children in this review. The trial registration describes a factorial study comparing deworming and vitamin A, which was delivered every six months for two years. ${ }^{79}$ The study began in 1999 and recruitment closed in 2004. The authors were contacted several times before our review was completed, but they did not provide information about the conduct of the study. We are unaware of any published results. We were therefore unable to assess eligibility, potential risk of bias, implementation of the intervention, or the generalisability of results. The authors did provide an early analysis of the primary outcome (rate ratio $=0.96,0.89$ to 1.03 ), as well as analyses of cause specific mortality and vitamin A serum concentration.

Details that might explain differences between DEVTA and our review were not available, but we find it unlikely that the results of our review can be explained by small study bias. Small studies could differ from mega-trials, but five trials in this review included more than 20000 participants and nine included more than 10000 participants. Furthermore, when the mortality data for DEVTA are included, results of the primary analysis remain significant with a fixed effect model, and that effect remains clinically meaningful.

\section{Heterogeneity}

Statistical heterogeneity suggests there might be differences in the effects of vitamin A supplementation across settings and populations, and we conducted prespecified subgroup analyses for all analyses with 10 or more studies.

Trials were conducted in 18 countries. As described above, vitamin A supplementation was associated with significant reductions in mortality in both Asia and Africa. While the difference between subgroups for the primary outcome was not significant, biochemical concentrations of vitamin A seem lower in Asia than in Africa, ${ }^{83}$ and our results are consistent with the hypothesis that the benefits of supplementation in Asia might be greater. ${ }^{94}$

For ethical reasons, some trials provided supplements to all children with symptoms of vitamin A deficiency (such as Bitot's spots). Exclusion of such children limits the magnitude of effects on vision outcomes, and such restrictions could contribute to observed heterogeneity across other outcomes in this review. Universal supplementation could result in larger benefits than those reported here.

A non-representative subset of studies reported data by age and sex, but these comparisons cannot be interpreted meaningfully except insofar as vitamin A supplementation was associated with significant reductions in mortality for all subgroups. All studies reporting the primary outcome used the standard dose recommended by WHO (table 2), except for one. ${ }^{52}$ While differences between these subgroups were significant, the results might be a statistical artefact; it is possible that small frequent doses will lead to large reductions in mortality, but it seems unlikely that a single supplement is more effective than multiple supplements of the same dose.

Though we did not find evidence of specific contributors to heterogeneity in this review, effects might differ according to baseline vitamin A status, the availability of other nutrients, or the prevalence of disease-for example, concomitant nutrient deficiencies could impair the bioavailability of vitamin A supplementation ${ }^{95}$ and differences in the prevalence of pathogens, sanitation, immunisation, and access to healthcare could affect the relative impact of vitamin A supplementation. Heterogeneity might be related to differences in the implementation of interventions, details of which are routinely under-reported in trials. ${ }^{96}$ For example, it is essential that providers distribute capsules effectively, that capsules have been stored properly and remain active, and that children ingest the supplements.

Subgroup analyses in this review were limited by the available data, and meta-analyses of group level data to explore individual level moderators should be interpreted with caution. Further analyses with individual patient data from randomised controlled trials and observational studies would be more informative.

\section{Implications for policy}

Vitamin A deficiency is a common condition that contributes to illness, blindness, and death; supplements can reduce these problems for children aged under 5 in low and middle income countries. National and regional supplementation programmes could be among the world's most cost effective public health interventions. ${ }^{97}$ If the risk of death for 190 million children deficient in vitamin A were reduced by $24 \%$, estimates from 
2008 suggest that over 600000 lives could be saved each year ${ }^{98}$ and 20 million disability adjusted life years would be gained. ${ }^{99}$

Although vitamin A supplementation has been available in many countries for over a decade, direct evidence for its contribution to reducing child mortality is not available. Many countries have experienced significant reductions in child mortality, ${ }^{5} 100$ and vitamin A supplementation programmes might have contributed to these declines.

Supplementation responds to an immediate need, but, in the long term, good nutrition requires reliable access to various fresh foods. Fortification, food distribution programmes, and horticultural developments might provide more permanent solutions. For example, growers could increase access to agricultural products like the orange fleshed sweet potato. ${ }^{101}$ Vitamin A could be added to rice, though fortification programmes must minimise risk of toxicity. Until such long term solutions are in place, supplementation should continue. As access to vitamin A increases, it will be important to continue to identify at risk groups and to deliver supplements to them.

Our review suggests potential pathways through which vitamin A supplementation reduces mortality. Increased vaccination against measles and other diseases will reduce the effect of vitamin A supplementation if its primary effect is to prevent infection; widespread supplementation, however, will remain important because vitamin A affects other systems-for example, supplementation can prevent blindness.

Based on these results, we strongly recommend vitamin A supplementation for children aged under 5 in areas at risk of vitamin A deficiency. Despite widespread efforts, vitamin A programmes do not reach all children who could benefit. ${ }^{15}$ Universal distribution could be achieved in several ways. Vitamin A supplementation can be provided when children receive other services like vaccinations, ${ }^{102}$ and it can be provided on a large scale. Child health days or other strategies might be used to increase awareness, ${ }^{103}$ and vitamin A uptake could be increased through national food programmes ${ }^{104}$ or through delivery by community health workers. ${ }^{105}$

\section{Implications for future research}

The effectiveness of vitamin A supplementation is so well established that further placebo controlled studies are not required. Nevertheless, this review does not identify the most effective dose or frequency of delivery. Large doses in the included studies were effective. Smaller, more frequent doses might produce larger reductions in mortality; more complex and burdensome programmes, however, could result in lower coverage. We suggest that policymakers consider including trials of dose and frequency in vitamin A distribution programmes. Other studies might investigate different delivery channels, including food supplementation, horticultural innovations, improved access to food, or psychosocial programmes to increase uptake of foods rich in vitamin A.

\section{Conclusions}

Our review reaffirms compelling evidence that vitamin A supplements can prevent death and illness in children aged 6 months to 5 years. Supplements are inexpensive and have few side effects. Further trials are needed to determine the most effective dose and frequency of supplementation, but placebo controlled trials would be unethical. Policymakers should continue working to provide supplements for all children at risk of deficiency, particularly those in low and middle income countries.
We are grateful to the Cochrane Collaboration for their assistance in preparing this review. We particularly thank the Cochrane Developmental Psychosocial and Learning Problems Group, including Jo Abbott, Chris Champion, and Laura MacDonald. Margaret Anderson developed the search strategy and Geraldine Macdonald edited the review. We thank the Cochrane Editorial Unit, particularly Toby Lasserson, Rachel Murphy, and Karla Soares-Weiser for extracting data; we thank David Tovey and Harriet MacLehose for advice and for helping to manage the project. We are grateful to Toby Lasserson for the table summarising of findings. Henry Ebron from DistillerSR provided assistance managing the data. We thank Julian Higgins and the Cochrane Methods Group for statistical advice and assistance. Anonymous peer reviewers offered helpful feedback on the protocol and the review, for which we are grateful. Contributors: All authors contributed to the planning, conduct, and reporting of this work, and to writing the abstract; specifically, the background (AI, EM-W), methods (EM-W, Al, KH), literature search ( $\mathrm{KH}, \mathrm{Al}, \mathrm{MYY}$ ), data extraction (EM-W, Al, KH, MYY), tables (Al, EM-W, $M Y Y)$, data analysis (EM-W, $K H)$, results (EM-W, $K H)$, discussion (EM-W, Al, KH), and overall supervision (ZAB). In addition to the authors Margaret Anderson developed the search strategy. Toby Lasserson, Rachel Murphy, and Karla Soares-Weiser extracted data. Toby Lasserson made the summary of findings table. Julian Higgins provided statistical advice and calculated intracluster correlation coefficient values. $\mathrm{ZAB}$ is guarantor.

Funding: The preparation of this review was funded by the Department of Nutrition for Health and Development, WHO, Switzerland. EMW and $\mathrm{KH}$ were supported by the University of Oxford's department of social policy and intervention and the centre for evidence-based intervention. $\mathrm{KH}$ received funding from a Marshall scholarship. AI, MYY, and ZAB were supported by Aga Khan University, Karachi, Pakistan.

Competing interests: All authors have completed the ICMJE uniform disclosure form at www.icmje.org/coi_disclosure.pdf (available on request from the corresponding author) and declare: no support from any organisation for the submitted work; no financial relationships with any organisations that might have an interest in the submitted work in the previous three years; no other relationships or activities that could appear to have influenced the submitted work.

Ethical approval: Not required.

Data sharing: Detailed tables and effects for each study are available from our Cochrane Review (www.cochrane.org).

Bates CJ. Vitamin A. Lancet 1995;345:31-5.

Green HN, Mellanby E. Vitamin A as an anti-infective agent. BMJ 1928;ii:691-6.

3 Sommer A, West KP. Vitamin A deficiency: health, survival, and vision. Oxford University Press, 1996.

4 Rice AL, West KP Jr, Black RE. Vitamin A deficiency. Global and regional burden of disease attributable to selected major risk factors. Vol 1. World Health Organization, 2004

5 Black RE, Cousens S, Johnson HL, Lawn JE, Rudan I, Bassani DG, et al. Global, regional, and national causes of child mortality in 2008: a systematic analysis. Lancet 2010;375:1969-87.

6 Black RE, Allen LH, Bhutta ZA, Caulfield LE, de Onis M, Ezzati M, et al. Maternal and child undernutrition: global and regional exposures and health consequences. Lancet 2008;371:243-60.

7 De Pee S, West CE, Muhilal M, Karyadi D, Hautvast JG. Lack of improvement in vitamin A status with increased consumption of dark-green leafy vegetables. Lancet 1995;346:75-81.

8 Tang G. Bioconversion of dietary provitamin A carotenoids to vitamin A in humans. Am J Clin Nutr 2010;91:1468-73S.

9 Smith FR, Goodman DS. Vitamin A transport in human vitamin A toxicity. N Engl J Med 1976;294:805-8.

10 Hathcock JN, Hattan DG, Jenkins MY, McDonald JT, Sundaresan PR, Wilkening VL. Evaluation of vitamin A toxicity. Am J Clin Nutr 1990;52:183-202.

11 Beaton G, Martorell R, Aronson K, Edmonston B, McCabe G, Ross A, et al. Effectiveness of Vitamin A supplementation in the control of young child morbidity and mortality in developing countries. United Nations Administrative Committee on Coordination/Sub-Committee on Nutrition, 1993.

12 Fawzi WW, Chalmers TC, Herrera MG, Mosteller F. Vitamin A supplementation and child mortality. A meta-analysis. JAMA 1993;269:898-903.

13 Glasziou PP, Mackerras DE. Vitamin A supplementation in infectious diseases: a meta-analysis. BMJ 1993;306:366-70.

14 World Health Organization. Vitamin A supplements: a guide to their use in prevention and treatment of vitamin A deficiency and xerophthalmia. WHO, 1997.

15 Bhutta ZA, Chopra M, Axelson H, Berman P, Boerma T, Bryce J, et al. Countdown to 2015 decade report (2000-10): taking stock of maternal, newborn, and child survival. Lancet 2010;375:2032-44. 


\section{What is already known on this topic}

Vitamin A is an essential nutrient; it must be obtained through diet

In low and middle income countries, many people (especially children) do not eat enough vitamin $A$

Vitamin A deficiency is related to vision problems and increased susceptibility to infectious disease and death

WHO recommends vitamin A supplements for children, pregnant women, and breastfeeding mothers

\section{What this study adds}

There have been 43 trials of vitamin A for children aged 6 months to 5 years old, including about 215633 children In low and middle income countries, vitamin A supplementation is associated with a $24 \%$ reduction in mortality Vitamin A supplementation might reduce mortality by preventing measles and diarrhoea; it also prevents blindness The evidence for vitamin $A$ is compelling and clear; further trials comparing vitamin $A$ with placebo would be unethical

16 Kapil U. Time to stop giving indiscriminate massive doses of synthetic vitamin A to Indian children. Public Health Nutr 2009:12:285-6.

17 Latham M. The great vitamin A fiasco. World Nutrition 2010;1:12-45.

18 Imdad AHK, Mayo-Wilson E, Yakoob MY, Bhutta ZA. Vitamin A supplementation for preventing morbidity and mortality in children six months to five years of age. Cochrane Database Syst -Rev 2010;5:CD008524

19 Higgins J, Green S. Cochrane handbook for systematic reviews of interventions. Version 5.0.1. Cochrane Collaboration, 2008.

20 DistillerSR. Web-based systematic review software. 2011. http://systematic-review.net/.

21 Hedges LV. Distribution theory for Glass's estimator of effect size and related estimators. $J$ Educ Stat 1981;6:107-28.

22 Higgins JP, Thompson SG. Quantifying heterogeneity in a meta-analysis. Stat Med 2002;21:1539-58.

23 Higgins JP, Thompson SG, Deeks JJ, Altman DG. Measuring inconsistency in meta-analyses. BMJ 2003;327:557-60.

24 Duval SJ, Tweedie RL. Trim and fill: a simple funnel-plot based method of accounting for publication bias in meta-analysis. Biometrics 2000;56:455-63.

25 Nordic Cochrane Centre. Review manager (RevMan). Version 5.0 [program]. Cochrane Collaboration, 2008

26 Biostat. Comprehensive meta-analysis. Version 2 [program]. Biostat, 2005.

27 Atkins D, Best D, Briss PA, Eccles M, Falck-Ytter Y, Flottorp S, et al. Grading quality of evidence and strength of recommendations. BMJ 2004;328:1490.

28 Agarwal D, Pandey C, Agarwal K. Vitamin A administration and preschool child mortality. Nutr Res 1995;15:669-80.

29 Arya S, Chellani H, Pandey J. Evaluation of safety of oral vitamin "A" megadose co-administered with measles vaccination. Indian Pediatr 2000;37:1341-7.

30 Bahl R, Kumar R, Bhandari N, Kant S, Srivastava R, Bhan MK. Vitamin A administered with measles vaccine to nine-month-old infants does not reduce vaccine immunogenicity. Jutr 1999;129:1569-73.

31 Barreto ML, Santos LM, Assis AM, Araujo MP, Farenzena GG, Santos PA, et al. Effect of vitamin A supplementation on diarrhoea and acute lower-respiratory-tract infections in young children in Brazil. Lancet 1994;344:228-31.

32 Benn CS, Aaby P, Bale C, Olsen J, Michaelsen KF, George E, et al. Randomised trial of effect of vitamin A supplementation on antibody response to measles vaccine in Guinea-Bissau, West Africa. Lancet 1997;350:101-5.

33 Biswas R, Biswas AB, Manna B, Bhattacharya SK, Dey R, Sarkar S. Effect of vitamin A supplementation on diarrhoea and acute respiratory tract infection in children. A double blind placebo controlled trial in a Calcutta slum community. Eur J Epidemiol 1994;10:57-61.

34 Cheng L, Chang Y, Wang EL, Brun T, Geissler C. Impact of large-dose vitamin A supplementation on childhood diarrhoea, respiratory disease and growth. Eur J Clin Nutr 1993;47:88-96.

35 Cherian T, Sneha V, Raghupathy P, Ratnam S, Chandra RK. Effect of Vitamin A supplementation on the immune response to measles vaccination. Vaccine 2003;21:2418-20.

36 Chowdhury S, Kumar R, Ganguly NK, Kumar L, Walia BN. Effect of vitamin A supplementation on childhood morbidity and mortality. Indian J Med Sci 2002;56:259-64.

37 Daulaire NM, Starbuck ES, Houston RM, Church MS, Stukel TA, Pandey MR. Childhood mortality after a high dose of vitamin A in a high risk population. BMJ 1992;304:207-10.

38 Dibley MJ, Sadjimin T, Kjolhede CL, Moulton LH. Vitamin A supplementation fails to reduce incidence of acute respiratory illness and diarrhea in preschool-age Indonesian children. J Nutr 1996;126:434-42.

39 Donnen P, Brasseur D, Dramaix M, Vertongen F, Zihindula M, Muhamiriza M, et al. Vitamin A supplementation but not deworming improves growth of malnourished preschool children in eastern Zaire. J Nutr 1998;128:1320-7.

40 Florentino RF, Tanchoco CC, Ramos AC, Mendoza TS, Natividad EP, Tangco JB, et al. Tolerance of preschoolers to two dosage strengths of vitamin A preparation. Am J Clin Nutr 1990;52:694-700.

41 Herrera MG, Nestel P, el Amin A, Fawzi WW, Mohamed KA, Weld L. Vitamin A supplementation and child survival. Lancet 1992;340:267-71.

42 Kartasasmita CB, Rosmayudi O, Deville W, Demedts M. Plasma retinol level, vitamin A supplementation and acute respiratory infections in children of $1-5$ years old in a developing country. Tuber Lung Dis 1995;76:563-9.

43 Lima AA, Soares AM, Lima NL, Mota RM, Maciel BL, Kvalsund MP, et al. Effects of vitamin A supplementation on intestinal barrier function, growth, total parasitic, and specific Giardia spp infections in Brazilian children: a prospective randomized, double-blind, placebo-controlled trial. J Pediatr Gastroenterol Nutr 2010;50:309-15.

44 Lin J, Lai X, Qin J, Song F, Zhang Y, Yao P, et al. Effect of beta-carotene supplementation on health and growth of vitamin $\mathrm{A}$ deficient children in China rural villages: a randomized controlled trial. e-SPEN 2009;4:e17-21.

45 Lin J, Song F, Yao P, Yang X, Li N, Sun S, et al. Effect of vitamin A supplementation on immune function of well-nourished children suffering from vitamin A deficiency in China. Eur J Clin Nutr 2008;62:1412-8.
46 Long KZ, Montoya Y, Hertzmark E, Santos JI, Rosado JL. A double-blind, randomized, clinical trial of the effect of vitamin $\mathrm{A}$ and zinc supplementation on diarrheal disease and respiratory tract infections in children in Mexico City, Mexico. Am J Clin Nutr 2006;83:693-700.

47 Long KZ, Rosado JL, DuPont HL, Hertzmark E, Santos JI. Supplementation with vitamin A reduces watery diarrhoea and respiratory infections in Mexican children. Br J Nutr 2007;97:337-43.

48 Pant CR, Pokharel GP, Curtale F, Pokhrel RP, Grosse RN, Lepkowski J, et al. Impact of nutrition education and mega-dose vitamin $A$ supplementation on the health of children in Nepal. Bull World Health Org 1996;74:533-45.

49 Pinnock CB, Douglas RM, Badcock NR. Vitamin A status in children who are prone to respiratory tract infections. Aust Paediatr J 1986;22:95-9.

50 Pinnock CB, Douglas RM, Martin AJ, Badcock NR. Vitamin A status of children with a history of respiratory syncytial virus infection in infancy. Aust Paediatr J 1988;24:286-9.

51 Rahman MM, Vermund SH, Wahed MA, Fuchs GJ, Baqui AH, Alvarez JO. Simultaneous zinc and vitamin A supplementation in Bangladeshi children: randomised double blind controlled trial. BMJ 2001;323:314-8.

52 Rahmathullah L, Underwood BA, Thulasiraj RD, Milton RC, Ramaswamy K, Rahmathullah $\mathrm{R}$, et al. Reduced mortality among children in southern India receiving a small weekly dose of vitamin A. N Engl J Med 1990;323:929-35.

53 Ramakrishnan U, Latham MC, Abel R. Vitamin A supplementation does not improve growth of preschool children: a randomized, double-blind field trial in south India. J Nutr 1995;125:202-11.

54 Ranjini EK, Cherian T, Balasubramaniam KA, Raghupathy P. Vitamin A supplementation in children with recurrent respiratory infections. Indian Pediatr 2001;38:771-4.

55 Reddy V, Vijayaraghavan K, Mathur KK. Effect of deworming and vitamin A administration on serum vitamin A levels in preschool children. J Trop Pediatr 1986;32:196-9.

56 Ross DA, Binka FN, Dollimore N, Smith PG, Addy HA, Tomkins AM, et al. Vitamin A supplementation in northern Ghana: effects on clinic attendances, hospital admissions, and child mortality. Lancet 1993;342:7-12.

57 Semba RD, Muhilal M, Scott AL, Natadisastra G, Wirasasmita S, Mele L, et al. Depressed immune response to tetanus in children with vitamin A deficiency. J Nutr 1992;122:101-7.

58 Semba RD, Munasir Z, Beeler J, Akib A, Muhilal M, Audet S, et al. Reduced seroconversion to measles in infants given vitamin $A$ with measles vaccination. Lancet 1995:345:1330-2.

59 Sempertegui F, Estrella B, Camaniero V, Betancourt V, Izurieta R, Ortiz W, et al. The beneficial effects of weekly low-dose vitamin $A$ supplementation on acute lower respiratory infections and diarrhea in Ecuadorian children. Pediatrics 1999;104:e1.

60 Shankar AH, Genton B, Semba RD, Baisor M, Paino J, Tamja S, et al. Effect of vitamin A supplementation on morbidity due to Plasmodium falciparum in young children in Papua New Guinea: a randomised trial. Lancet 1999;354:203-9.

61 Sinha DP, Bang FB. The effect of massive doses of vitamin A on the signs of vitamin A deficiency in preschool children. Am J Clin Nutr 1976;29:110-5.

62 Smith JC, Makdani D, Hegar A, Rao D, Douglass LW. Vitamin A and zinc supplementation of preschool children. J Am Coll Nutr 1999;18:213-22.

63 Sommer A, Tarwotjo I, Djunaedi E, West KP Jr, Loeden AA, Tilden R, et al. Impact of vitamin A supplementation on childhood mortality. A randomised controlled community trial. Lancet 1986;1:1169.

64 Stabell C, Bale C, Pedro da Silva A, Olsen J, Aaby P. No evidence of fontanelle-bulging episodes after vitamin A supplementation of 6- and 9-month-old infants in Guinea Bissau. Eur J Clin Nutr 1995;49:73-4.

65 Stansfield SK, Muller PL, Lerebours G, Augustin A. Vitamin A supplementation and increased prevalence of childhood diarrhoea and acute respiratory infections. Lancet 1993;342:578-82.

66 Van Agtmaal EJ, Bloem MW, Speek AJ, Saowakontha S, Schreurs HP, van Haeringen $\mathrm{NJ}$. The effect of vitamin A supplementation on tear fluid retinol levels of marginally nourished preschool children. Curr Eye Res 1988;7:43-8.

67 Venkatarao T, Ramakrishnan R, Nair NG, Radhakrishnan S, Sundaramoorthy L, Koya PK, et al. Effect of vitamin A supplementation to mother and infant on morbidity in infancy. Indian Pediatr 1996;33:279-86.

68 Vijayaraghavan K, Radhaiah G, Surya Prakasam B, Sarma KVR, Reddy V. Effect of massive dose vitamin $\mathrm{A}$ on morbidity and mortality in Indian children. Lancet 1990;336:1342-5.

69 West KP Jr, Pokhrel RP, Katz J, LeClerq SC, Khatry SK, Shrestha SR, et al. Efficacy of vitamin A in reducing preschool child mortality in Nepal. Lancet 1991;338:67-71.

70 Bhaskaram P, Rao KV. Enhancement in seroconversion to measles vaccine with simultaneous administration of vitamin A in 9-months-old Indian infants. Indian J Pediatr 1997;64:503-9.

71 Bloem MW, van Agtmaal EJ, Speek AJ, Saowakontha S, Schreurs WHP. Vitamin A intervention: short-term effects of a single, oral, massive dose on iron metabolism. Am J Clin Nutr 1990;51:76-9.

72 Kothari G. The effect of vitamin A prophylaxis on morbidity and mortality among children in urban slums in Bombay. J Trop Pediatr 1991;37:141. 
73 Wu Z, Ouyang L. Impact of vitamin A on the immune function of infants. China Trop Med 2007;7:540-1.

74 Bahl R, Taneja S, Bhan MK. The impact of vitamin A supplementation on physical growth of children is dependent on season. Eur J Clin Nutr 1997;51:26-9.

75 Semba RD, Natadisastra G, Muhilal M, Sommer A. Response of Bitot's spots in preschool children to vitamin A treatment. Am J Ophthalmol 1990;110:416-20.

76 Semba RD, Ndugwa C, Perry RT, Clark TD, Jackson JB, Melikian G, et al. Effect of periodic vitamin A supplementation on mortality and morbidity of human immunodeficiency virus-infected children in Uganda: a controlled clinical trial. Nutrition 2005;21:25-31.

77 Yang HM, Mao M, Wan CM. Vitamin A for treating measles in children. Cochrane Database Syst Rev 2005;4:CD001479.

78 Aklamati E, Brown KH, Mulenga M, Kafwembe E, Peerson JM, Stephensen C, et al. Impact of high-dose vitamin A supplements on vitamin A status of 3-4 $y$ old Zambian boys. Faseb J 2006;20:A1050.

79 DEVTA: cluster-randomised trial in 1 million children in North India. ILSI Micronutrient Forum, 2007.

80 Ramakrishnan U, Darnton-Hill I. Assessment and control of vitamin A deficiency disorders. J Nutr 2002;132:2947-53S

81 Bhutta ZA. Effect of infections and environmental factors on growth and nutritional status in developing countries. J Pediatr Gastroenterol Nutr 2006;43:S13-21.

82 Demissie T, Ali A, Mekonnen Y, Haider J, Umeta M. Demographic and health-related risk factors of subclinical vitamin A deficiency in Ethiopia. J Health Popul Nutr 2009;27:666-73.

83 WHO. Global prevalence of vitamin A deficiency in populations at risk 1995-2005. WHO global database on vitamin A deficiency. World Health Organization, 2009.

84 Imdad A, Haider BA, Bhutta ZA. Nutrition interventions for maternal and child health and survival.Vol 1. Oxford University Press, 2010

85 Dwan K, Altman DG, Arnaiz JA, Bloom J, Chan AW, Cronin E, et al. Systematic review of the empirical evidence of study publication bias and outcome reporting bias. PLOS One 2008;3:e3081.

86 Kirkham JJ, Dwan KM, Altman DG, Gamble C, Dodd S, Smyth R, et al. The impact of outcome reporting bias in randomised controlled trials on a cohort of systematic reviews. BMJ 2010;340:c365.

87 Mayo-Wilson E, Montgomery P. Missing data in systematic reviews: a table might help (poster). Joint Colloquium of the Cochrane and Campbell Collaborations, 2010.

88 Gogia S, Sachdev H. Vitamin A supplementation for the prevention of morbidity and mortality in infants six months of age or less (review). Cochrane Database Syst Rev 2008:4:CD007480

89 LeLorier J, Gregoire G, Benhaddad A, Lapierre J, Derderian F. Discrepancies between meta-analyses and subsequent large randomized, controlled trials. N Engl J Med 1997;337:536-42.

90 Peto R, Collins R, Gray R. Large-scale randomized evidence: large, simple trials and overviews of trials. J Clin Epidemiol 1995;48:23-40.

91 Higgins JP, Spiegelhalter DJ. Being sceptical about meta-analyses: a Bayesian perspective on magnesium trials in myocardial infarction. Int J Epidemiol 2002;31:96-104.
92 Bailar JC 3rd. The promise and problems of meta-analysis. N Engl J Med 1997;337:559-61. 93 Peto R, Baigent C. Trials: the next 50 years. Large scale randomised evidence of moderate benefits. BMJ 1998;317:1170-1.

94 Imdad A, Yakoob MY, Sudfeld C, Haider BA, Black RE, Bhutta ZA. Impact of vitamin A supplementation on infant and childhood mortality. BMC Public Health 2011;11:S20.

95 Villamor E, Fawzi WW. Vitamin A supplementation: implications for morbidity and mortality in children. $J$ Infect Dis 2000;182:S122-33.

96 Mayo-Wilson E. Reporting implementation in randomized trials: proposed additions to the consolidated standards of reporting trials statement. Am J Public Health 2007;97:630-3.

97 Fawzi WW. The benefits and concerns related to vitamin A supplementation. $J$ Infect Dis 2006;193:756-9.

98 Bhutta ZA, Ahmed T, Black RE, Cousens S, Dewey K, Giugliani E, et al. What works? Interventions for maternal and child undernutrition and survival. Lancet2008:371:417-40.

99 World Health Organization. Global health risks: mortality and burden of disease attributable to selected major risks. WHO, 2009

100 You D, Wardlaw T, Salama P, Jones G. Levels and trends in under-5 mortality, 1990-2008. Lancet 2010;375:100-3.

101 Klemm RD, West KP Jr, Palmer AC, Johnson Q. Randall P, Ranum P, et al. Vitamin A fortification of wheat flour: considerations and current recommendations. Food Nutr Bull 2010;31: S47-61.

102 Wallace A, Dietz V, Cairns KL. Integration of immunization services with other health interventions in the developing world: what works and why? Systematic literature review. Trop Med Int Health 2009;14:11-9.

103 Oliphant NP, Mason JB, Doherty T, Chopra M, Mann P, Tomlinson M, et al. The contribution of child health days to improving coverage of periodic interventions in six African countries. Food Nutr Bull 2010;31:S248-63.

104 Semba RD, de Pee S, Sun K, Bloem MW, Raju VK. The role of expanded coverage of the national vitamin A program in preventing morbidity and mortality among preschool children in India. J Nutr 2009;140:208-12S.

105 Lassi ZS, Haider BA, Bhutta ZA. Community-based intervention packages for reducing maternal and neonatal morbidity and mortality and improving neonatal outcomes. Cochrane Database Syst Rev 2010;11:CD007754.

Accepted: 07 July 2011

\section{Cite this as: BMJ 2011;343:d5094}

This is an open-access article distributed under the terms of the Creative Commons Attribution Non-commercial License, which permits use, distribution, and reproduction in any medium, provided the original work is properly cited, the use is non commercial and is otherwise in compliance with the license. See: http://creativecommons.org/licenses/by$\mathrm{nc} / 2.0 /$ and http://creativecommons.org/licenses/by-nc/2.0/legalcode. 


\section{Tables}

\begin{tabular}{|c|c|c|c|c|c|c|}
\hline Study & Country & Age (months) & $\begin{array}{c}\text { No of } \\
\text { participants }\end{array}$ & $\begin{array}{l}\text { Follow-up } \\
\text { (months) }\end{array}$ & Dose (1000 IU) & Frequency ${ }^{*}$ \\
\hline Agarwal $1995^{28}$ & India & $0-72$ & $17778 \dagger$ & 15,27 & 50 at $1-6 \mathrm{~m} ; 100$ at $>6 \mathrm{~m}$ & $0,4,8,12 \mathrm{~m}$ \\
\hline Arya $2000^{29}$ & India & 9-12 & 256 & 24 hour & 100 & 1 dose \\
\hline Bahl $1999^{30}$ & India & $6-9$ & 618 & 4 & 100 & 1 dose \\
\hline Barreto $1994^{31}$ & Brazil & $6-48$ & 1240 & 12 & 100 at $<12 \mathrm{~m} ; 200 \geq 12 \mathrm{~m}$ & $0,4,8,12 \mathrm{~m}$ \\
\hline Benn $1997^{32}$ & Guinea Bissau & 6-9 & 462 & 12 & 100 & 1 dose \\
\hline Biswas $1994^{33}$ & India & $12-71$ & 180 & 6 & 200 & 1 dose \\
\hline Cheng $1993^{34}$ & China & $6-36$ & 198 & 12 & 100 at $<12 \mathrm{~m} ; 200 \geq 12 \mathrm{~m}$ & $4,10 \mathrm{~m}$ \\
\hline Cherian $2003^{35}$ & India & 6-9 & 395 & 6 & 100 & 1 dose \\
\hline Chowdhury $2002^{\beta 36}$ & India & $<120$ & 1520 & 15 & $\begin{array}{c}50 \text { at }<6 \mathrm{~m} ; 100 \text { at } 6-12 \mathrm{~m} ; \\
200 \text { at }>12 \mathrm{~m}\end{array}$ & $0,5,10 \mathrm{~m}$ \\
\hline Daulaire $1992 \ddagger^{37}$ & Nepal & $1-59$ & $7197 \dagger$ & 5 & $\begin{array}{c}50 \text { at }<6 \mathrm{~m} ; 100 \text { at } 6-12 \mathrm{~m} ; \\
200 \text { at } \geq 12 \mathrm{~m}\end{array}$ & 1 dose \\
\hline Dibley $1996^{38}$ & Indonesia & $6-47$ & 1405 & 24 & 103 at $<12 \mathrm{~m} ; 206$ at $\geq 12 \mathrm{~m}$ & $0,4,8,12,16,20,24 \mathrm{~m}$ \\
\hline Donnen $1998 \ddagger^{39}$ & Congo (Zaire) & $0-72$ & 235 & 12 & 100 at $<12 \mathrm{~m} ; 200$ at $\geq 12 \mathrm{~m}$ & $0,6,12 \mathrm{~m}$ \\
\hline Florentino $1990^{40}$ & Philippines & $12-72$ & 2471 & 1 week & $100,200 \S$ & 1 dose \\
\hline Herrera $1992^{41}$ & Sudan & $9-72$ & 28753 & 18 & 200 & $0,6,12,18 \mathrm{~m}$ \\
\hline Kartasamita $1995^{42}$ & Indonesia & $12-54$ & 267 & 12 & 200 & $0,6,12 \mathrm{~m}$ \\
\hline Lima $2010 \ddagger^{43}$ & Brazil & $2-108$ & 79 & 36 & 100 at $<12 \mathrm{~m} ; 200$ at $\geq 12 \mathrm{~m}$ & $0,4,8 \mathrm{~m}$ \\
\hline Lin $2008^{45}$ & China & $24-84$ & 70 & 3 & 100 & $0,0.5,1,1.5,2,2,5,3 \mathrm{~m}$ \\
\hline Lin $2009^{44}$ & China & $6-84$ & 86 & 3 & 100 & $0,1,2,3 \mathrm{~m}$ \\
\hline Long $2006^{46}$ & Mexico & $6-15$ & 786 & 12 & 20 at $<12 \mathrm{~m} ; 45$ at $\geq 12 \mathrm{~m}$ & $0,2,4,6,8,10,12 \mathrm{~m}$ \\
\hline Long $2007^{47}$ & Mexico & $6-15$ & 195 & 12 & 20 at $<12 \mathrm{~m} ; 45$ at $\geq 12 \mathrm{~m}$ & $0,2,4,6,8,10,12 \mathrm{~m}$ \\
\hline Pant $1996 \ddagger^{48}$ & Nepal & $6-120$ & $25301 \dagger$ & 24 & 100 at $6-12 \mathrm{~m} ; 200$ at $\geq 12 \mathrm{~m}$ & 1 dose \\
\hline Pinnock $1986^{49}$ & Australia & $1-48$ & 147 & 20 weeks & 3.9 & 3/week for 20 weeks \\
\hline Pinnock $1988^{50}$ & Australia & $0-24$ & 206 & 12 & 14 & Weekly for 1 year \\
\hline Rahman $2001^{51}$ & Bangladesh & $12-35$ & 800 & 6 & 200 & 1 dose \\
\hline Rahmathullah $1990^{52}$ & India & $6-60$ & $15419 \dagger$ & 12 & 8.333 & Weekly for 1 year \\
\hline Ramakrishnan $1995^{53}$ & India & $6-36$ & 583 & 12 & 100 at $<12 \mathrm{~m} ; 200$ at $\geq 12 \mathrm{~m}$ & $0,4,8,12 \mathrm{~m}$ \\
\hline Ranjini $2001^{54}$ & India & $12-60$ & 61 & 6 & 200 & 1 dose \\
\hline Reddy $1986^{55}$ & India & $12-60$ & 487 & 12 & 200 & 1 dose \\
\hline Ross 1993 health $^{56}$ & Ghana & 6-59 & 1455 & 12 & 100 at $6-12 \mathrm{~m} ; 200$ at $\geq 12 \mathrm{~m}$ & $0,4,8,12 \mathrm{~m}$ \\
\hline 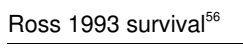 & Ghana & $6-90$ & $21906+$ & 12 & 100 at $6-12 \mathrm{~m} ; 200$ at $\geq 12 \mathrm{~m}$ & $0,4,8,12,16,20,24 \mathrm{~m}$ \\
\hline Semba $1992^{57}$ & Indonesia & $36-72$ & 236 & 1 & 200 & 1 dose \\
\hline Semba $1995^{58}$ & Indonesia & 6 & 336 & 6 & 100 & 1 dose \\
\hline Sempertegui $1999^{59}$ & Ecuador & $6-36$ & 400 & 9 & 10 & Weekly for $40 \mathrm{w}$ \\
\hline Shankar $1999^{60}$ & Papa New Guinea & $6-60$ & 480 & 13 & 100 at $<12 \mathrm{~m} ; 200$ at $\geq 12 \mathrm{~m}$ & $0,4,8,12 \mathrm{~m}$ \\
\hline Sinha $1976^{61}$ & India & 2-54 & 306 & 12 & 200 & $0,4,8,12 \mathrm{~m}$ \\
\hline Smith $1999^{62}$ & Belize & $26-66$ & 51 & 6 & 10 & Weekly for $26 \mathrm{w}$ \\
\hline Sommer $1986 \ddagger^{63}$ & Indonesia & $0-71$ & $29236 \dagger$ & 9-13 & 200 & $0,6 \mathrm{~m}$ \\
\hline Stabell $1995^{64}$ & Guinea Bissau & 6 & 68 & 30 & 100 & $0,3 \mathrm{~m}$ \\
\hline Stansfield $1993^{65}$ & Haiti & $6-83$ & 13651 & 12 & 100 at $6-11 \mathrm{~m} ; 200$ at $\geq 12 \mathrm{~m}$ & $0,4,8 \mathrm{~m}$ \\
\hline van Agtmaal $1988^{66} \ddagger$ & Thailand & 37 & 30 & 4 & 200 & 1 dose \\
\hline Venkatarao $1996^{67}$ & India & 6 & 612 & 6 & 200 & 1 dose \\
\hline Vijyagharvan $1990^{68}$ & India & $12-60$ & $15775 \dagger$ & 12 & 200 & $0,6,12 \mathrm{~m}$ \\
\hline West $1991^{69}$ & Nepal & $6-72$ & $28630 \dagger$ & 16 & 100 at $6-11 \mathrm{~m} ; 200$ at $\geq 12 \mathrm{~m}$ & $0,4,8,12 \mathrm{~m}$ \\
\hline
\end{tabular}


Table 1 (continued)

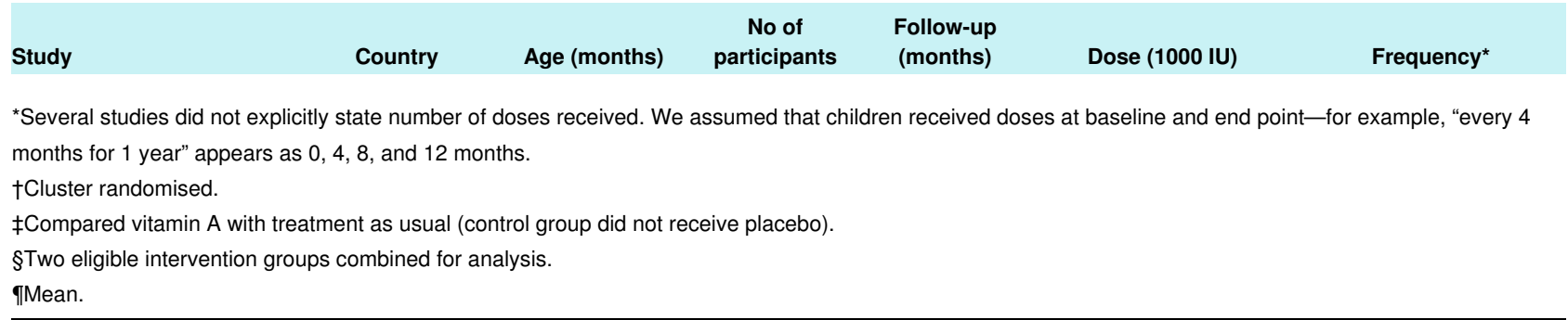


Table 2/ Subgroup analyses for all cause mortality at longest follow-up in studies of effect of vitamin A supplementation in children aged under 5

\begin{tabular}{|c|c|c|c|c|c|}
\hline \multirow[b]{2}{*}{ Subgroup (test for difference) } & \multirow[b]{2}{*}{ All trials } & \multicolumn{2}{|c|}{ No $(\%)$ in primary analysis } & \multirow[b]{2}{*}{ Fixed effect rate ratio $(95 \% \mathrm{Cl})$} & \multirow[b]{2}{*}{ Heterogeneity: $I^{2}(\%)$; } \\
\hline & & Trials & Participants & & \\
\hline All studies ${ }^{28-69}$ & 43 & $16(37)$ & $194483(90)$ & $0.76(0.69$ to 0.83$)$ & $48 \% ; 29.10(P=0.02)$ \\
\hline \multicolumn{6}{|l|}{ Location $(P=0.12)$ : } \\
\hline All & - & $16(37)$ & $194483(90)$ & - & - \\
\hline Africa $^{3339415664}$ & 6 & $5(12)$ & $52811(25)$ & 0.85 (0.73 to 0.98$)$ & $59 \% ; 9.81(P=0.04)$ \\
\hline Australia $^{4950}$ & 2 & 0 & 0 & - & - \\
\hline Asia $^{28-30} 33-38404244454851-55575860616366-69$ & 28 & $10(23)$ & $140432(65)$ & $0.69(0.61$ to 0.79$)$ & $40 \% ; 15.00(P=0.09)$ \\
\hline Latin America ${ }^{31} 434647596265$ & 7 & $1(2)$ & $1240(<1)$ & $1.00(0.14$ to 7.08$)$ & - \\
\hline \multicolumn{6}{|l|}{ Setting (NA): } \\
\hline All & - & $16(37)$ & $194483(90)$ & - & - \\
\hline (Peri)urban $293032333536424345-4749-515459$ & 16 & $2(5)$ & $1982(<1)$ & NA & NA \\
\hline Rural| $^{28} 313437-414448525355-5860-69$ & 27 & $14(33)$ & $192501(89)$ & NA & NA \\
\hline \multicolumn{6}{|l|}{ Dose $(P=0.02)$ : } \\
\hline All & - & $16(37)$ & $194483(90)$ & 0.76 (0.69 to 0.83$)$ & $48 \% ; 29.10(P=0.02)$ \\
\hline WHO (single) $)^{293032333637404851545557586667}$ & 15 & $4(9)$ & $33572(16)$ & $0.66(0.52$ to 0.83$)$ & $0 \% ; 2.15(P=0.54)$ \\
\hline WHO $(4-6 m)^{28313436383941-475356606163-656869}$ & 18 & $11(26)$ & $147933(69)$ & $0.81(0.72$ to 0.90$)$ & $48 \% ; 19.17(P=0.04)$ \\
\hline More frequent ${ }^{44-47495052596264}$ & 10 & $1(2)$ & $15419(7)$ & $0.46(0.30$ to 0.71$)$ & - \\
\hline \multicolumn{6}{|l|}{$\mathrm{Age}^{\star}(\mathrm{P}=0.46):$} \\
\hline All & 一 & $5(12)$ & $61544(29)$ & $0.66(0.56$ to 0.77$)$ & $0.0 \% ; 6.77(\mathrm{P}=0.45)$ \\
\hline $\begin{array}{l}\text { 6-12 months } \\
6769\end{array}$ & 32 & $4(9)$ & $4739(2)$ & 0.59 (0.43 to 0.82$)$ & $15 \% ; 3.51(P=0.32)$ \\
\hline $12-60$ months $^{2831333436-5759-666869}$ & 37 & $4(9)$ & $56805(26)$ & $0.68(0.57$ to 0.81$)$ & $0.0 \% ; 2.72(P=0.44)$ \\
\hline \multicolumn{6}{|l|}{ Sex† $(P=0.89)$ : } \\
\hline All & - & $5(12)$ & $85568(40)$ & $0.80(0.70$ to 0.91$)$ & $34 \% ; 10.69(P=0.15)$ \\
\hline Males $^{28-69}$ & 43 & $5(12)$ & $43567(20)$ & $0.80(0.66$ to 0.97$)$ & $62 \% ; 7.79(P=0.05)$ \\
\hline Females $^{28-69}$ & 43 & $5(12)$ & $42001(20)$ & 0.79 (0.65 to 0.95$)$ & $0.0 \% ; 2.87(P=0.41)$ \\
\hline With DEVTA ${ }^{28-6979}$ & 44 & $17(39)$ & $1194483(98)$ & $0.88(0.84$ to 0.94$)$ & $64 \% ; 44.31(\mathrm{P}<0.001)$ \\
\hline
\end{tabular}

$\mathrm{NA}=$ not available; planned analysis not conducted; DEVTA=deworming and vitamin A trial.

${ }^{*}$ For primary outcome, trials reported mortality for children $<12$ months, ${ }^{33}$ children $>12$ months, ${ }^{64}$ or both. ${ }^{38} 5370$

†One trial reporting data by sex reported no events, ${ }^{46}$ and four trials appear in both analysis. ${ }^{38426470}$ 


\begin{tabular}{|c|c|c|c|c|c|c|}
\hline Outcome & $\begin{array}{c}\text { No }(\%) \text { of trials } \\
(n=43)\end{array}$ & $\begin{array}{l}\text { No (\%) of participants } \\
(n=215633)\end{array}$ & $\begin{array}{c}\text { Rate ratio }(95 \% \mathrm{Cl}), \text { fixed } \\
\text { effect }\end{array}$ & Heterogeneity: $I^{2} ; X^{2}$ & $\begin{array}{l}\text { Follow-up } \\
\text { (weeks) }\end{array}$ & $\begin{array}{l}\text { Quality of evidence } \\
\text { (GRADE) }\end{array}$ \\
\hline \multicolumn{7}{|l|}{ Primary outcome } \\
\hline All cause mortality & $16(37)$ & $194483(90)$ & 0.76 (0.69 to 0.83 ) & $48 \% ; 29.10(P=0.02)$ & $12-96$ & High \\
\hline \multicolumn{7}{|l|}{ Cause specific mortality } \\
\hline Diarrhoea 28363741525667 & $7(16)$ & $90951(42)$ & 0.72 (0.57 to 0.91$)$ & $2 \% ; 6.12(P=0.41)$ & $48-104$ & Moderate \\
\hline Measles $^{2837415256}$ & $5(12)$ & $88261(41)$ & 0.80 (0.51 to 1.24$)$ & $0 \% ; 0.40(\mathrm{P}=0.98)$ & $52-104$ & Moderate \\
\hline Meningitis ${ }^{283656}$ & $3(7)$ & $41204(19)$ & 0.57 (0.17 to 1.88$)$ & $0 \% ; 0.75(P=0.69)$ & $48-108$ & Low \\
\hline LRTII 28363741525667 & $7(16)$ & $90951(42)$ & 0.78 (0.54 to 1.14$)$ & $14 \% ; 7.00(P=0.32)$ & 48-104 & Low \\
\hline \multicolumn{7}{|l|}{ IIIness } \\
\hline \multicolumn{7}{|l|}{ Diarrhoea: } \\
\hline $\begin{array}{l}\text { Incidence } \\
\text { 47 } 535931333966736384041\end{array}$ & $13(30)$ & $37710(17)$ & 0.85 (0.82 to 0.87$)$ & $95 \% ; 217.99(P<0.01)$ & $24-60$ & Low \\
\hline Prevalence $^{354765}$ & $2(5)$ & $14437(7)$ & 1.08 (1.05 to 1.12$)$ & $87 \% ; 15.76(P<0.01)$ & 48 & Very low \\
\hline \multicolumn{7}{|l|}{ Malaria: } \\
\hline Incidence $^{60}$ & $1(2)$ & $480(<1)$ & 0.73 (0.60 to 0.88$)$ & NA & 52 & Very low \\
\hline Prevalence $^{56}$ & $2(5)$ & $23361(11)$ & 0.72 (0.41 to 1.28$)$ & $0 \% ; 0.02(P=0.88)$ & 48 & Moderate \\
\hline \multicolumn{7}{|l|}{ Measles: } \\
\hline Incidence ${ }^{30-32364158}$ & $6(14)$ & $19566(9)$ & 0.50 (0.37 to 0.67$)$ & $0 \% ; 0.55$ (0.99); & $16-78$ & High \\
\hline Prevalence & $0(0)$ & $0(0)$ & NA & NA & NA & NA \\
\hline \multicolumn{7}{|l|}{ LRTI: } \\
\hline Incidence 31343642475967 & $7(16)$ & $18179(8)$ & $1.14(0.95$ to 1.37$)$ & $22 \% ; 7.66(0.26)$ & $24-60$ & Very low \\
\hline Prevalence $^{46}$ & $1(2)$ & $786(0.4)$ & 0.46 (0.21 to 1.03$)$ & NA & 48 & Very low \\
\hline
\end{tabular}

$\mathrm{LRTI}=$ lower respiratory tract infection. 
Table 4| Summary of pooled analyses for admission to hospital, vision, vitamin A deficiency, and adverse events in studies of effect of vitamin A supplementation in children aged under 5

\begin{tabular}{|c|c|c|c|c|c|c|}
\hline Outcome & $\begin{array}{c}\text { No }(\%) \text { of trials } \\
(n=43)\end{array}$ & $\begin{array}{l}\text { No }(\%) \text { of participants } \\
(n=215633)\end{array}$ & $\begin{array}{c}\text { Rate ratio }(95 \% \mathrm{Cl}) \text {, fixed } \\
\text { effect }\end{array}$ & Heterogeneity: $I^{2} ; X^{2}$ & $\begin{array}{l}\text { Follow-up } \\
\text { (weeks) }\end{array}$ & $\begin{array}{l}\text { Quality of evidence } \\
\text { (GRADE) }\end{array}$ \\
\hline \multicolumn{7}{|l|}{ Admission to hospital } \\
\hline All cause ${ }^{56}$ & $1(2)$ & $1185(0.5)$ & 0.64 (0.40 to 1.02$)$ & NA & 48 & Very low \\
\hline Diarrhoea $^{34}$ & $1(2)$ & $198(<1)$ & 0.25 (0.01 to 6.11$)$ & NA & 48 & Very low \\
\hline$\left.\underline{\mathrm{LRT}}\right|^{34}$ & $1(2)$ & $198(<1)$ & 0.11 (0.01 to 2.06$)$ & NA & 48 & Very low \\
\hline \multicolumn{7}{|l|}{ Vision } \\
\hline \multicolumn{7}{|l|}{ Bitot's spots: } \\
\hline Incidence $^{41}$ & $1(2)$ & $28753(13)$ & 0.93 (0.76 to 1.14$)$ & NA & 72 & Very low \\
\hline Prevalence ${ }^{48616369}$ & $4(9)$ & $63278(29)$ & 0.45 (0.33 to 0.61$)$ & $64 \% ; 8.25(P=0.04)$ & $36-96$ & Moderate \\
\hline \multicolumn{7}{|l|}{ Night blindness: } \\
\hline Incidence $^{41}$ & $1(2)$ & $28753(13)$ & 0.53 (0.28 to 0.99$)$ & NA & 72 & Low \\
\hline Prevalence ${ }^{6369}$ & $2(5)$ & $22972(11)$ & $0.32(0.21$ to 0.50$)$ & $0 \% ; 0.19(P=0.66)$ & $52-68$ & Moderate \\
\hline \multicolumn{7}{|l|}{ Xerophthalmia: } \\
\hline Incidence ${ }^{314169}$ & $3(7)$ & $58623(27)$ & 0.85 (0.70 to 1.03$)$ & $63 \% ; 2.69(P=0.10)$ & $48-72$ & Low \\
\hline Prevalence $^{316369}$ & $2(5)$ & $57866(27)$ & 0.31 (0.22 to 0.45$)$ & $0 \% ; 0.22(P=0.64)$ & $36-64$ & Moderate \\
\hline \multicolumn{7}{|l|}{ Vitamin A deficiency } \\
\hline Number deficient ${ }^{3854} 5660$ & $4(9)$ & $2262(1)$ & 0.71 (0.65 to 0.78$)$ & $78 \% ; 13.58(P<0.01)$ & $24-96$ & High \\
\hline $\begin{array}{l}\text { Serum concentration } \\
\text { S4 } 439850545-575960\end{array}$ & $13(30)$ & $6623(3)$ & $\mathrm{g}=0.31(0.26$ to 0.36$)$ & $95 \% ; 270.23(P<0.01)$ & 4-96 & Moderate \\
\hline \multicolumn{7}{|l|}{ Adverse events } \\
\hline Vomiting $^{29} 4061$ & $3(7)$ & $2994(1)$ & 2.75 (1.81 to 4.19$)$ & $21 \% ; 2.53(P=0.28)$ & 48 hours & Very low \\
\hline Bulging fontanelle $e^{29} 3064$ & $3(7)$ & $885(<1)$ & 5.00 (0.24 to 103.72$)$ & NA & 48 hours & Low \\
\hline
\end{tabular}

$\mathrm{NA}=$ not available; $\mathrm{LRTI}=$ lower respiratory tract infection. 


\section{Figures}

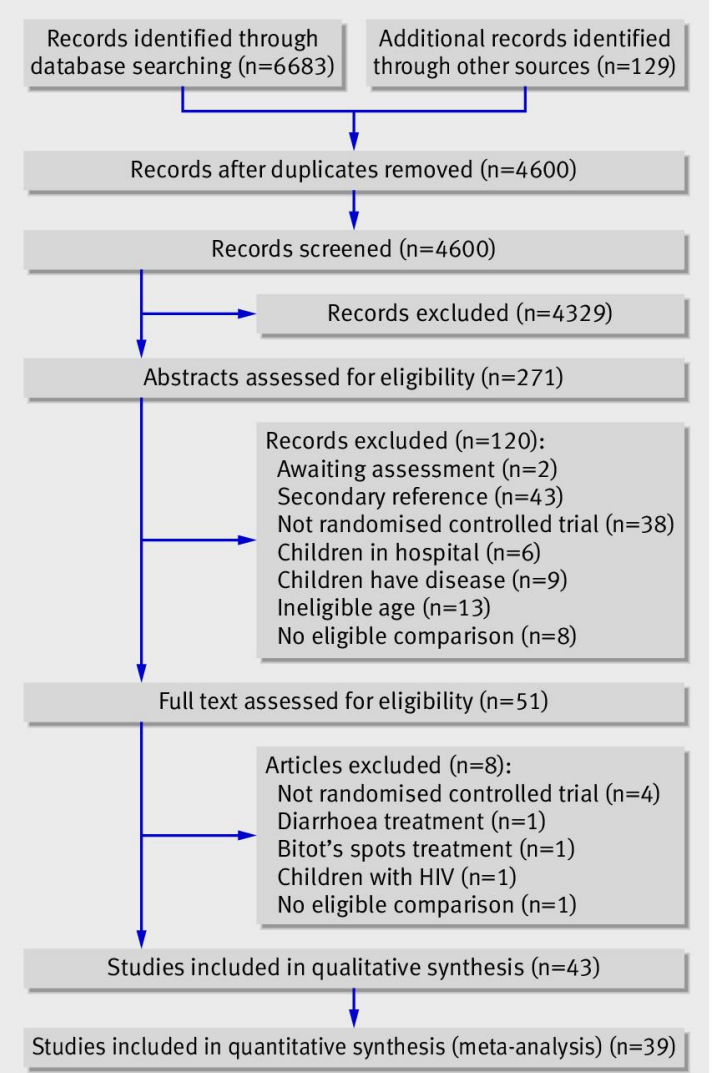

Fig 1 Identification of studies to include in review of effect of vitamin A supplementation on mortality, illness, and blindness in children aged under 5 


\section{Key}
+ Low risk of bias
? Unclear
- High risk of bias

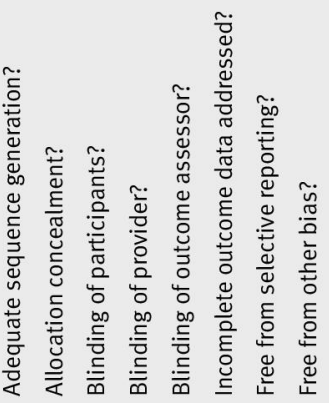

\begin{tabular}{|l|l|l|l|l|l|l|l|l|} 
Agarwal $1995^{28}$ & $?$ & $?$ & $?$ & $?$ & $?$ & $?$ & $?$ & $?$ \\
\hline
\end{tabular}

\begin{tabular}{l|l|l|l|l|l|l|l|l} 
Arya $2000^{29}$ & - & $?$ & + & + & + & - & - & +
\end{tabular}

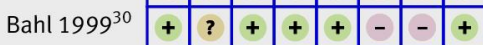

\begin{tabular}{l|l|l|l|l|l|l|l|l|} 
Barreto $1994^{31}$ & ? & + & + & + & + & + & ? & + \\
\cline { 2 - 7 } & &
\end{tabular}

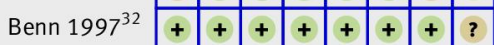

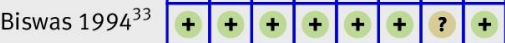

\begin{tabular}{l|l|l|l|l|l|l|l|l|} 
Cheng $1993^{34}$ & $?$ & $?$ & + & + & + & - & $?$ & + \\
\cline { 2 - 7 } & & + &
\end{tabular}

\begin{tabular}{l|l|l|l|l|l|l|l|l} 
Cherian $2003^{35}$ & $?$ & + & $?$ & $?$ & $?$ & - & - & $?$
\end{tabular}

\begin{tabular}{|l|l|l|l|l|l|l|l|l|} 
Chowdhury $_{2} 2002^{36}$ & $?$ & $?$ & $?$ & $?$ & $?$ & - & $?$ & $?$ \\
\cline { 2 - 7 } & &
\end{tabular}

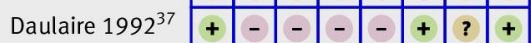

Dibley $1996^{38}$\begin{tabular}{l|llllllllll} 
& + & + & + & + & + & + & + & +
\end{tabular}

\begin{tabular}{ll|l|l|l|l|l|l|l|} 
Donnen $1998^{39}$ & $\mathbf{?}$ & $\boldsymbol{?}$ & $\mathbf{?}$ & $\mathbf{?}$ & $\mathbf{?}$ & $\mathbf{+}$ & $\mathbf{?}$ & $\mathbf{+}$ \\
\cline { 2 - 7 }
\end{tabular}

\begin{tabular}{ll|lllllllll}
\multirow{2}{*}{ Florentino $1990^{40}$} & $?$ & $?$ & + & + & + & + & + & +
\end{tabular}

\begin{tabular}{l|l|l|l|l|l|l|l|l} 
Herrera $1992^{41}$ & - & $?$ & + & + & + & + & $?$ & $?$
\end{tabular}

\begin{tabular}{ll|l|l|l|l|l|l|l|l|}
\cline { 2 - 7 } Kartasasmita $1995^{42}$ & $?$ & $?$ & $?$ & $?$ & $?$ & - & $?$ & $?$ \\
\hline
\end{tabular}

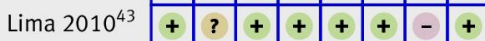

\begin{tabular}{l|l|l|l|l|l|l|l|l}
\multirow{2}{*}{$\operatorname{Lin} 2008^{44}$} & $\boldsymbol{?}$ & $?$ & + & $?$ & $?$ & + & - & $?$
\end{tabular}

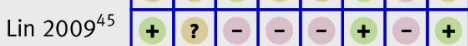

\begin{tabular}{l|l|l|l|l|l|l|l|l} 
Long $2006^{46}$ & + & + & + & + & + & + & $?$ & +
\end{tabular}

\begin{tabular}{l|llllllllll} 
Long $2007^{47}$ & + & + & + & + & + & + & $?$ & +
\end{tabular}

\begin{tabular}{ll|l|l|l|l|l|l|l} 
Pant $1996^{48}$ & + & $?$ & $?$ & $?$ & $?$ & - & - & $?$ \\
\cline { 2 - 7 }
\end{tabular}

\begin{tabular}{l|l|l|l|l|l|l|l|l|} 
Pinnock $1986^{49}$ & + & $?$ & + & + & + & + & $?$ & +
\end{tabular}

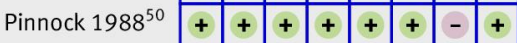

\begin{tabular}{ll|lllllllll} 
Rahman $2001^{51}$ & + & + & + & + & + & + & ? & +
\end{tabular}

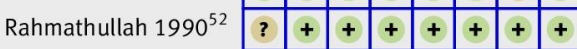

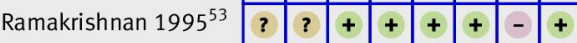

\begin{tabular}{l|l|l|l|l|l|l|l|l|} 
Ranjini $2001^{54}$ & $?$ & $?$ & $?$ & $?$ & $?$ & $?$ & $?$ & $?$ \\
\hline
\end{tabular}

\begin{tabular}{|l|l|l|l|l|l|l|l|l|}
$\operatorname{Reddy} 1986^{55}$ & $\mathbf{3}$ & $\mathbf{?}$ & $\mathbf{?}$ & $\mathbf{?}$ & $\mathbf{?}$ & $\mathbf{?}$ & $\mathbf{?}$ & $\mathbf{?}$ \\
\cline { 2 - 7 } & & &
\end{tabular}

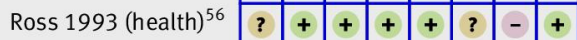

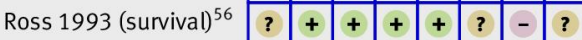

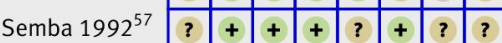

Semba $1995^{58}$\begin{tabular}{l|llllllllll} 
& + & + & + & + & + & - & $?$ & $?$
\end{tabular}

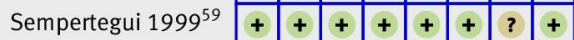

\begin{tabular}{ll|llllllll} 
Shankar $1999^{60}$ & + & + & + & + & + & + & $?$ & +
\end{tabular}

\begin{tabular}{ll|l|l|l|l|l|l|l|} 
Sinha $1976^{61}$ & $?$ & $?$ & + & + & + & $?$ & $?$ & +
\end{tabular}

\begin{tabular}{l|l|l|l|l|l|l|l|l|} 
Smith $1999^{62}$ & $?$ & $?$ & $?$ & $?$ & $?$ & $?$ & $?$ & $?$
\end{tabular}

\begin{tabular}{|l|l|l|l|l|l|l|l|l|}
\multirow{2}{*}{ Sommer $1986^{63}$} & $?$ & $?$ & $?$ & $?$ & $?$ & $?$ & $?$ & $?$ \\
\cline { 2 - 8 }
\end{tabular}

\begin{tabular}{ll|l|l|l|l|l|l|l|l|} 
Stabell $1995^{64}$ & $\boldsymbol{?}$ & $\boldsymbol{?}$ & $\boldsymbol{?}$ & $\boldsymbol{?}$ & $\boldsymbol{?}$ & $\boldsymbol{?}$ & $\mathbf{?}$ & $\mathbf{?}$ \\
\cline { 2 - 8 }
\end{tabular}

\begin{tabular}{l|lllllllll} 
Stansfield $1993^{65}$ & $\mathbf{-}$ & $\mathbf{+}$ & $\mathbf{+}$ & $\mathbf{+}$ & $\mathbf{+}$ & $\mathbf{+}$ & $\mathbf{-}$ & $\mathbf{+}$
\end{tabular}

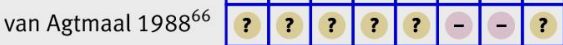

\begin{tabular}{ll|l|l|l|l|l|l|l|} 
Venkatarao $1996^{67}$ & $?$ & $?$ & + & + & + & $?$ & + & + \\
\cline { 2 - 7 }
\end{tabular}

Vijayaraghavan $1990^{68}$

West $1991^{69}$

Fig 2 Assessment of risk of bias in studies on effect of vitamin A supplementation on mortality, illness, and blindness in children aged under 5 
Study

Dibley $1996^{38}$

Barreto $1994^{31}$

Chowdhury $2002^{36}$

Venkatarao $1996^{67}$

Benn $1997^{32}$

Donnen $1998^{39}$

Ross 1993 (health) ${ }^{56}$

Agarwal $1995^{28}$

Vijayaraghavan $1990^{68}$

Pant $1996^{48}$

Rahmathullah $1990^{52}$

Sommer $1986^{63}$

Daulaire $1992^{37}$

Herrera $1992^{41}$

West $1991^{69}$

Ross 1993 (survival) ${ }^{56}$

Total

Test for heterogeneity: $\chi^{2}=29.10$,

$\mathrm{df}=15, \mathrm{P}=0.002, \mathrm{I}^{2}=48 \%$

0.10 .2

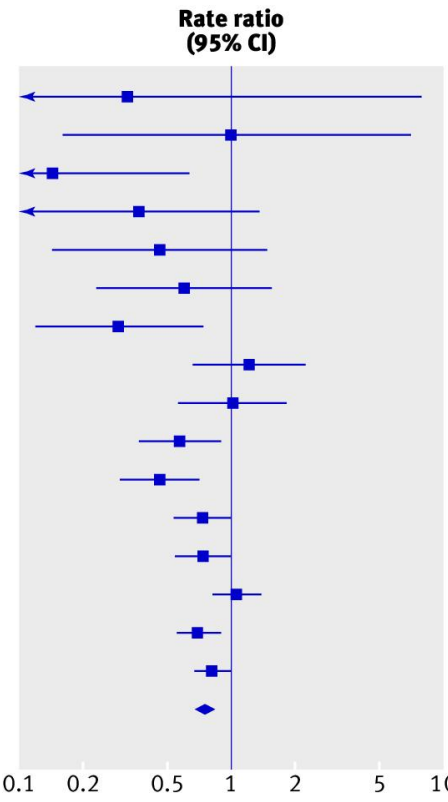

Fig 3 All cause mortality in studies on effect of vitamin A supplementation in children aged under 5

\section{Study}

Dibley $1996^{38}$

Barreto $1994^{31}$

Chowdhury $2002^{36}$

Venkatarao $1996^{67}$

Benn $1997^{32}$

Donnen $1998^{39}$

Ross 1993 (health) ${ }^{56}$

Agarwal $1995^{28}$

Vijayaraghavan $1990^{68}$

Pant $1996^{48}$

Rahmathullah $1990^{52}$

Sommer $1986^{63}$

Daulaire $1992^{37}$

Herrera $1992^{41}$

West $1991^{69}$

Ross 1993 (survival) ${ }^{56}$

DEVTA $^{79}$

Total

Test for heterogeneity: $\chi^{2}=44.31$,

$\mathrm{df}=16, \mathrm{P}<0.001, \mathrm{l}^{2}=64 \%$ including deworming and vitamin A (DEVTA) trial 


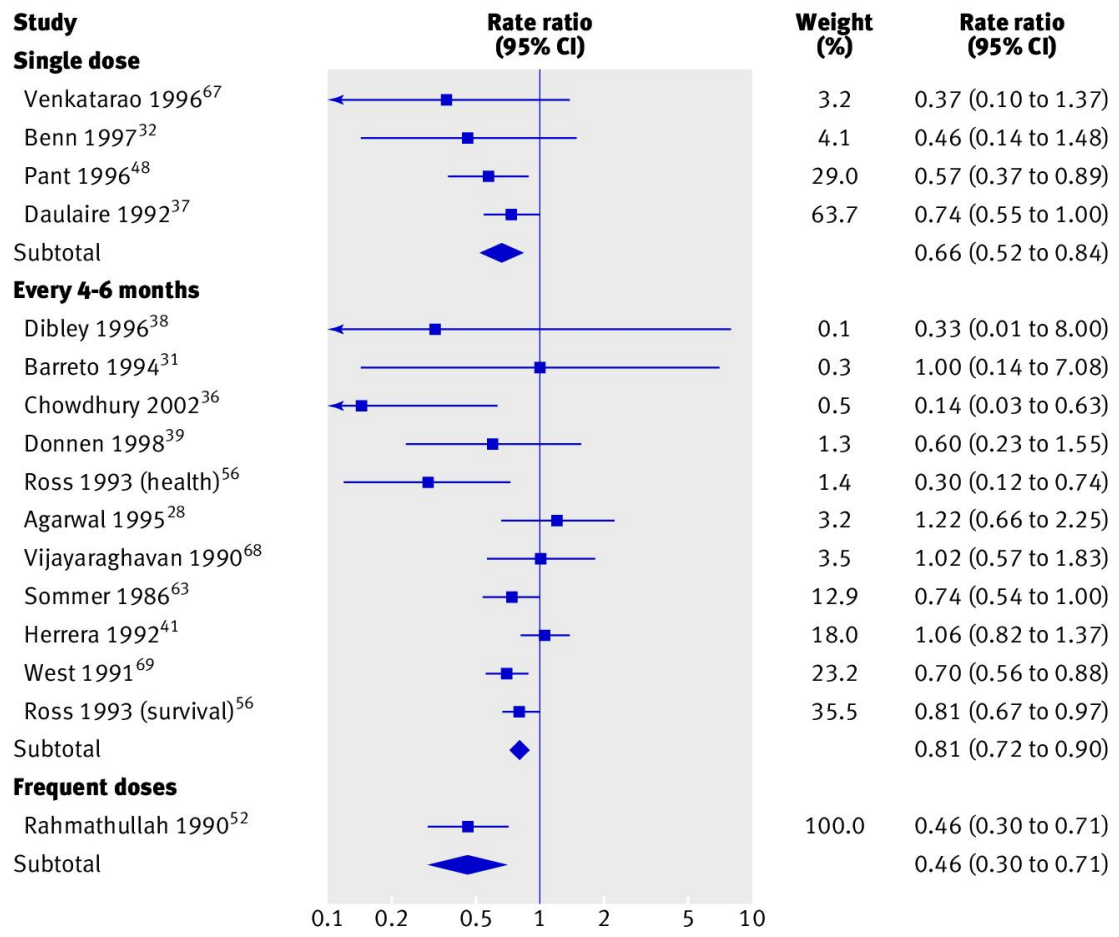

Fig 5 All cause mortality by dose in studies on effect of vitamin A supplementation in children aged under 5

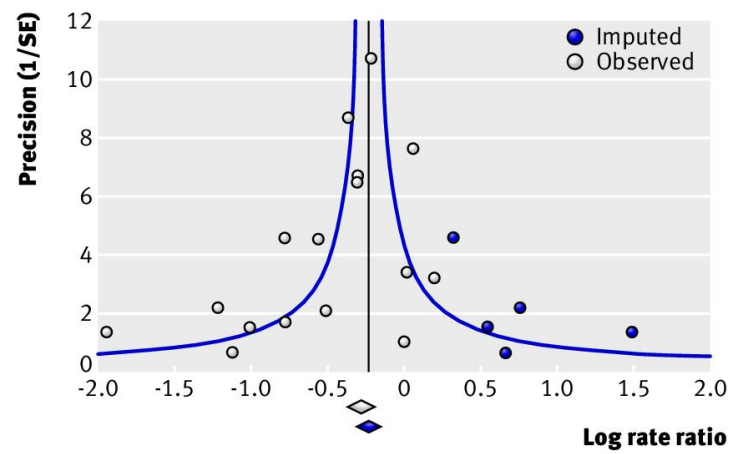

Fig 6 Mortality funnel plot with trim and fill in studies on effect of vitamin A supplementation in children aged under 5 . Observed=included studies. Imputed=observed effects trimmed to make funnel plot symmetrical, opposite effects imputed, trimmed studies and imputed effects replaced

\section{Study}

Arya $2000^{29}$

Florentino $1990^{40}$

Cheng $1993^{34}$

Herrera $1992^{41}$

Biswas $1994^{33}$

Venkatarao $1996^{67}$

Long $2007^{47}$

Sempertegui $1999^{59}$

Shankar $1999^{60}$

Dibley $1996^{38}$

Chowdhury $2002^{36}$

Barreto $1994^{31}$

Total

Test for heterogeneity: $\chi^{2}=15.76$,

$\mathrm{df}=2, \mathrm{P}<0.001, \mathrm{I}^{2}=87 \%$

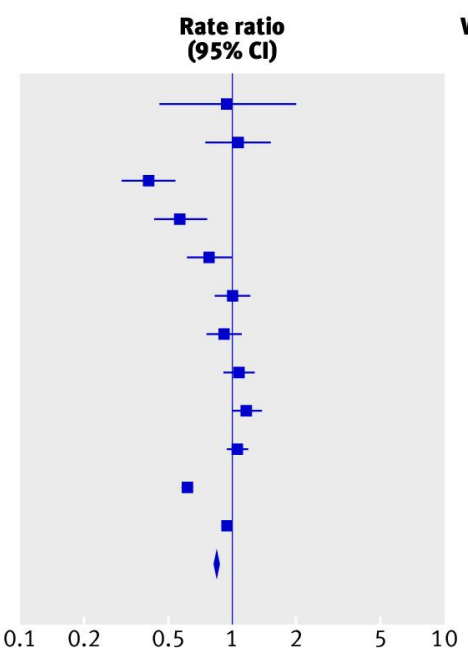


Fig 7 Incidence of diarrhoea in studies on effect of vitamin A supplementation in children aged under 5
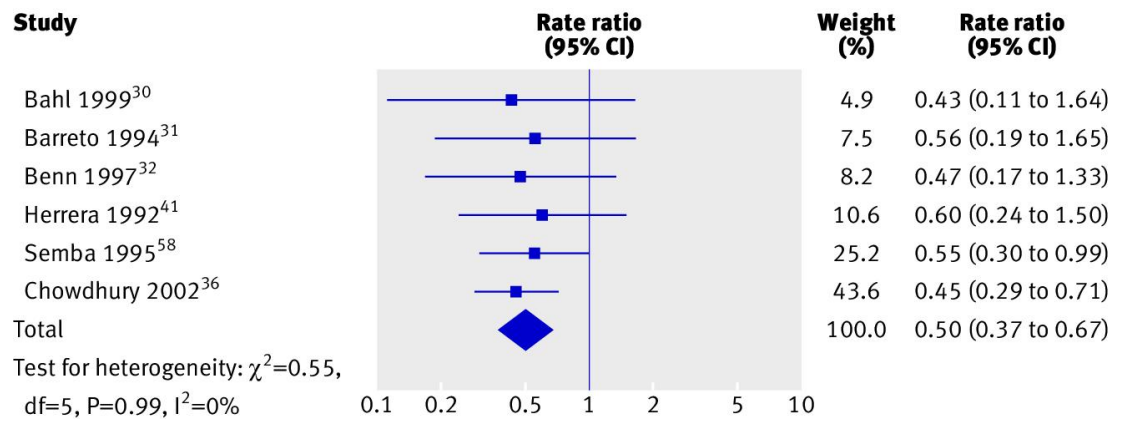

Fig 8 Incidence of measles in studies on effect of vitamin A supplementation in children aged under 5

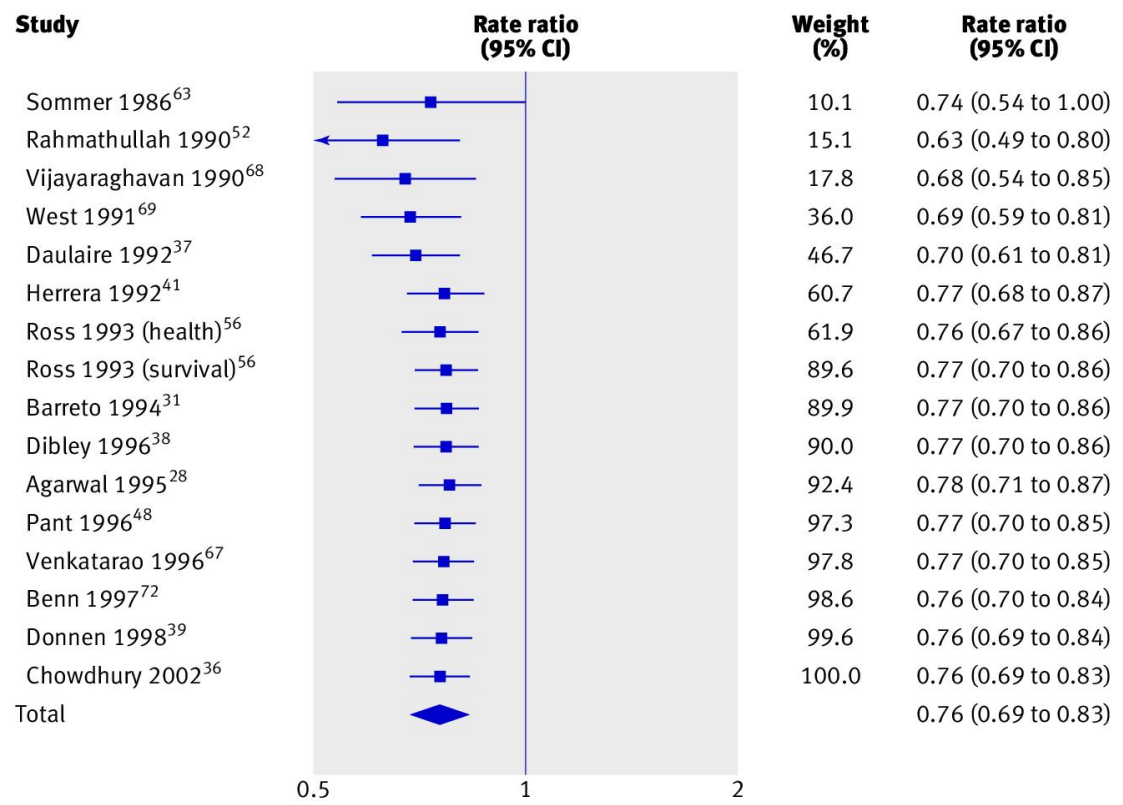

Fig 9 All cause mortality cumulative meta-analysis in studies on effect of vitamin A supplementation in children aged under 5 